EXPLORING THE RELATIONSHIP BETWEEN SOCIAL ISOLATION, LONELINESS AND HOUSING

by

Jennifer Lynn Wardle

B.Sc., University of British Columbia, 2009

\author{
A Major Research Paper \\ presented to Ryerson University \\ in partial fulfillment of the requirements for the degree of \\ Master of Planning \\ in \\ Urban Development
}

Toronto, Ontario, Canada, 2013

(C) Jennifer Lynn Wardle 2013 


\section{Author's Declaration}

I hereby declare that I am the sole author of this major research paper. This is a true copy of the major research paper, including any required final revisions, as accepted by my examiners.

I authorize Ryerson University to lend this major research paper to other institutions or individuals for the purpose of scholarly research

I further authorize Ryerson University to reproduce this major research paper by photocopying or by other means, in total or in part, at the request of other institutions or individuals for the purpose of scholarly research.

I understand that my major research paper may be made electronically available to the public. 


\title{
EXPLORING THE RELATIONSHIP BETWEEN SOCIAL ISOLATION, LONELINESS AND HOUSING
}

(C) Jennifer Lynn Wardle, 2013

Master of Planning

in

Urban Development

Ryerson University

\begin{abstract}
A significant demographic shift is underway in Canada. The aging of the population, which is expected to accelerate over the next two decades, is anticipated to create new issues and challenges for planners and policy makers. Issues of social isolation and loneliness have long been recognized as problems that affect seniors. Both social isolation and loneliness have been associated with significant implications for health and well-being, yet these issues have largely been discussed only in the fields of gerontology and health. This paper explores the relationships between social isolation, loneliness and housing. Key themes identified in the literature on social isolation and loneliness are used to inform a discussion on the potential for housing to help alleviate these problems. Four housing options, cohousing, congregate housing, home sharing and garden suites are presented. Each option presents a number of opportunities for greater socialization and companionship; however, each is similarly faced with a number of challenges. Despite the potential for these options to help reduce or alleviate these problems, none of the options presents a 'magic bullet' solution. Addressing social isolation and loneliness remains an extremely challenging problem for planning and greater research is needed to address the gaps in the literature.
\end{abstract}

Key words: housing, seniors, social isolation, loneliness, social relationships 


\section{ACKNOWLEDGEMENTS}

I would like to express a thank you, first and foremost to my supervisor, Professor Steven Webber. Thank you for patience, guidance and detailed feedback throughout this entire process. It has been deeply appreciated. I would also like to extend a thank you to my second reader, Professor Joseph Springer. Thank you for your enthusiasm and role in helping shape and guide the direction of this research and for always lending a thoughtful ear.

I would like to thank my parents and family who, despite the distance, have supported and encouraged me every step of the way. I also give my warmest thanks to all my classmates and now friends for whom I have shared this journey. 


\section{TABLE OF CONTENTS}

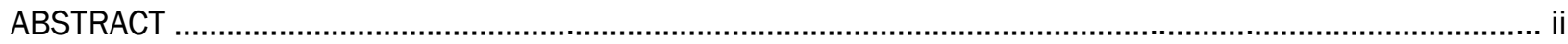

AUTHOR'S DECLARATION ...............................................................................................................

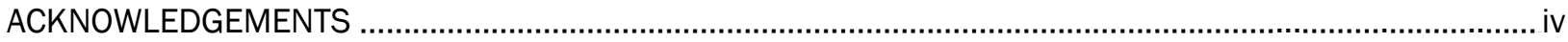

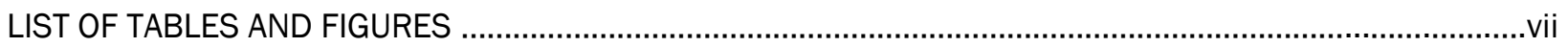

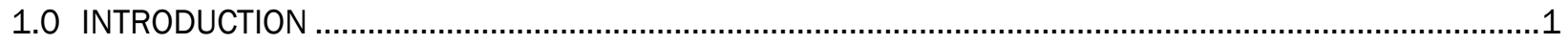

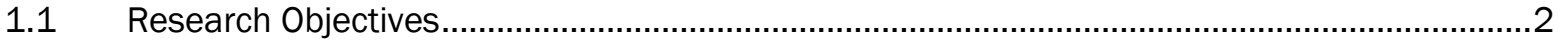

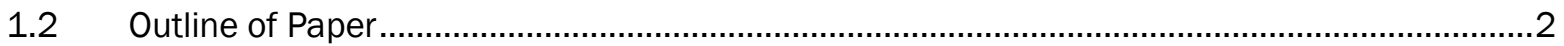

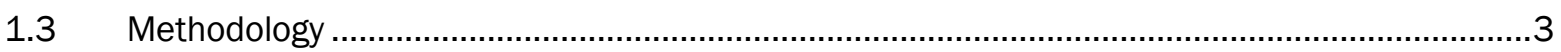

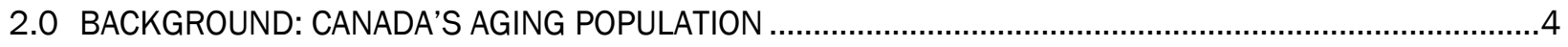

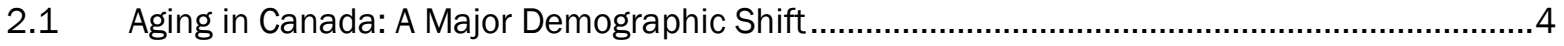

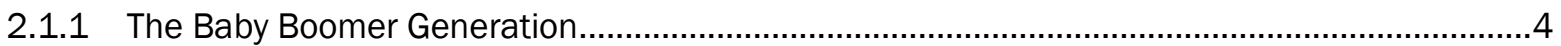

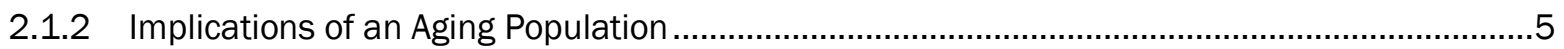

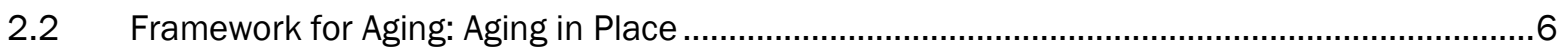

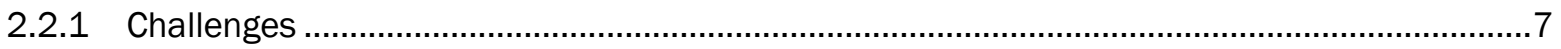

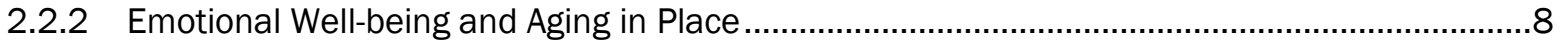

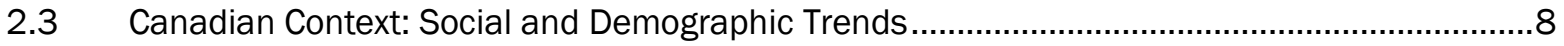

2.3.1 More People Living Alone and in Smaller Households..........................................................8

2.3.2 More People Living Longer, Healthier Lifestyles....................................................................

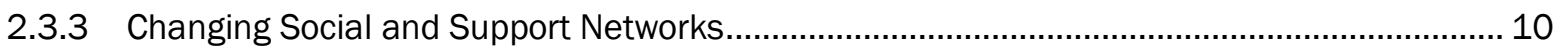

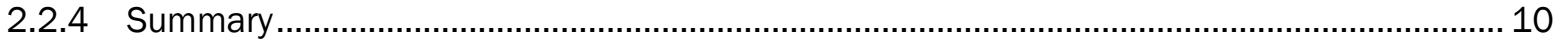

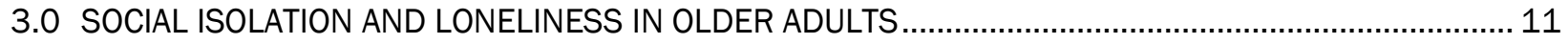

3.1 The Relationship between Social Isolation and Loneliness................................................... 11

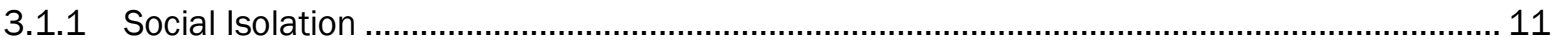

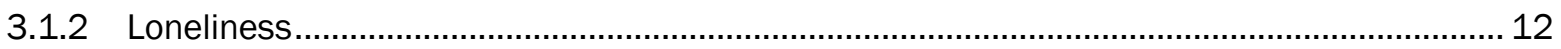

3.2 Consequences of Social Isolation and Loneliness ......................................................... 13

3.3 Who is Socially Isolated or Lonely? Risk Factors .................................................................. 14

3.3.1 Personal Background, Social and Cultural Factors ............................................................... 15

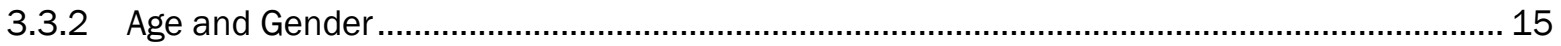




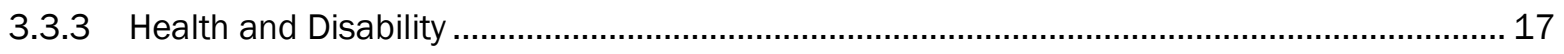

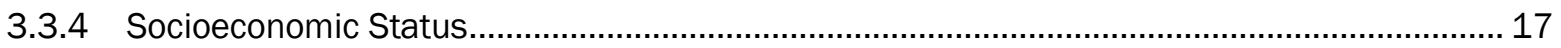

3.3.5 Living Arrangements and Living Alone ............................................................................. 17

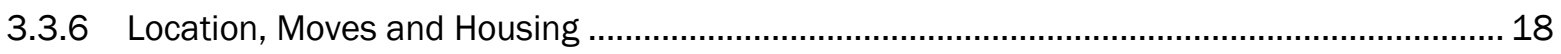

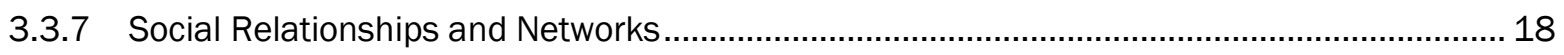

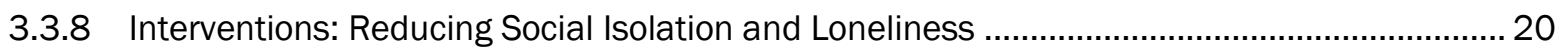

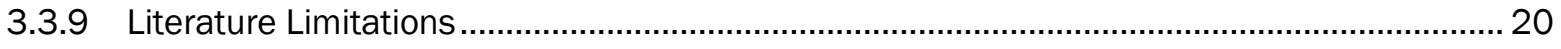

4.0 HOUSING OPTIONS TO RESPOND TO SOCIAL ISOLATION AND LONELINESS ..................................... 22

4.1 Continuum of Housing

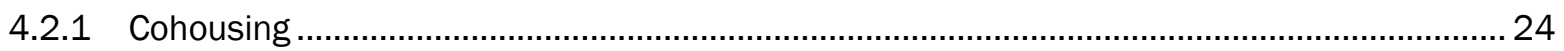

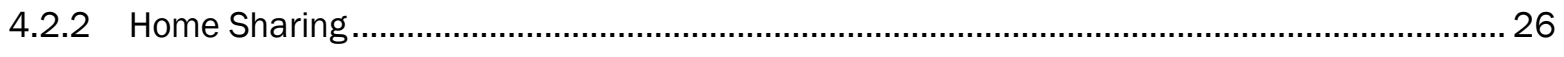

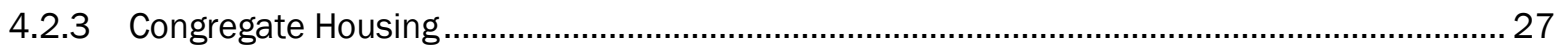

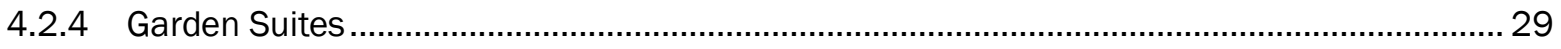

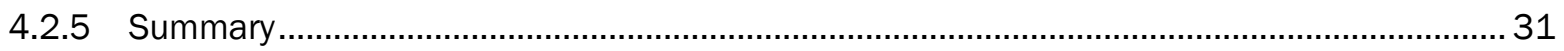

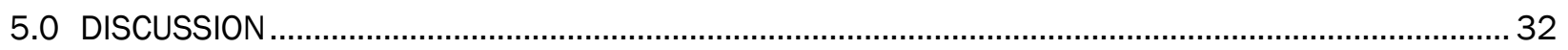

5.1 Can Housing Reduce Social Isolation and Loneliness? Four Options.................................... 32

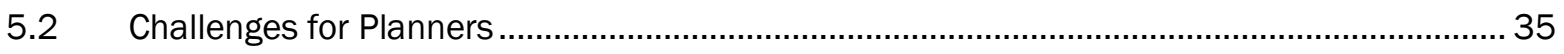

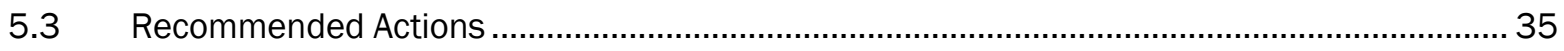

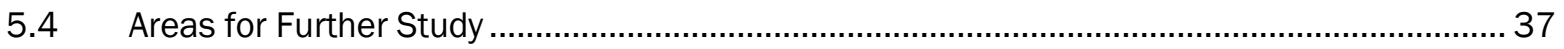

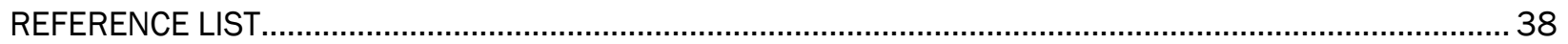




\section{LIST OF TABLES}

Table 1

Housing Continuum .

23

\section{LIST OF FIGURES}

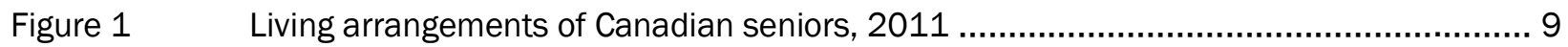

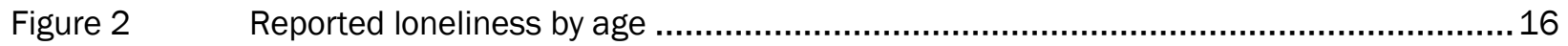

Figure $3 \quad$ Pleasant Hill Cohousing Community, Pleasant Hill, California...................................... 26

Figure $4 \quad$ Silver Sage Senior Cohousing, Boulder, Colorado ............................................. 26

Figure $5 \quad$ Abbeyfield Lakeside House, Toronto …................................................................ 29

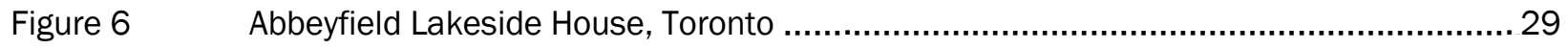

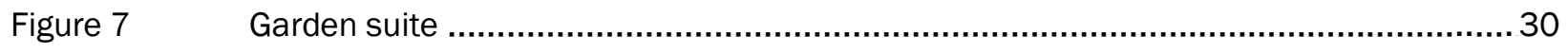

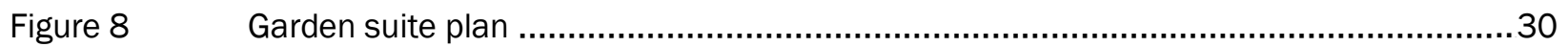




\subsection{INTRODUCTION}

The composition of Canada's population is changing and the proportion of older Canadians is growing quickly. Between 2011 and 2036, the number of seniors is expected to more than double, from 5.0 million to 10.4 million Canadians (Government of Canada, 2013). By 2036, an unprecedented one in four Canadians will be over the age of 65 . Growth of this segment of the population is largely attributed to the Baby Boomer Generation, the first of whom have only recently reached 65 in 2011. A number of other social and demographic trends underlie also this shift.

These seniors will create new challenges for governments, including placing higher demands on intergenerational transfers such as income supports and public services. This has raised concern and even some alarm as to the potential financial impact, sustainability and supportability of public services in the future (Cheal, 2002). Population aging is also occurring alongside a number of other widespread social and demographic trends. These include increased personal mobility, a higher proportion of single person households, smaller household sizes, fewer children and changes in social relationships. As the population ages, an increasing number of older Canadians will likely find themselves living alone, many with smaller families and social networks to rely upon than in the past.

The objective of this paper is to explore the relationship between social isolation, loneliness and housing. Research indicates that living conditions, including housing, are a primary social determinant of health (Raphael \& Mikkonen, 2010). However, social and demographic trends suggest that in the future,

many seniors may be living in housing that could be not only be inadequate for meeting their physical needs but could also be inadequate for meeting their social and emotional needs. Personal networks among seniors differ from those of other age groups. For many seniors, social networks are often characterized by fewer but more emotionally close relationships (Pushkar \& Arbuckle, 2006, as cited in Federal/Provincial/Territorial Committee of Officials, 2006). However, these small networks may leave some seniors vulnerable. While aging in place remains the dominant preference among the majority of seniors, changing relationships and reduced support may have implications for becoming socially isolated and experiencing loneliness, both of which are associated with a number of negative health and wellbeing outcomes. Research suggests that loneliness is associated with reduced mobility and decline in ability to perform activities of daily living (Peissinotto, Stijacic \& Covinsky, 2012), poor sleep quality (Cacioppo et al., 2002) and an increased likelihood of admittance to a nursing home (Russell et al., 1997). Research on older individuals and the general population suggests that there may be characteristics which make some individuals more vulnerable to social isolation and loneliness. Given the 
potential consequences for health and well-being, greater attention and awareness is needed by planners and policy makers. This paper explores social isolation and loneliness, social relationships and the ability of housing to respond to these issues.

A variety of living arrangements and housing options have been developed for older individuals, many of which seek to provide greater opportunity for companionship, socialization and a sense of community. These options include, but are not limited to, cohousing, congregate housing, home sharing and garden suites. In theory, these options may help alleviate social isolation and loneliness among society's oldest members. This paper will explore the characteristics of each housing option to better understand the ways in which these options may potentially reduce social isolation, alleviate loneliness and enhance the quality of life for older people. This paper will bring together literature from the fields of housing, planning, gerontology and health. Interventions that address social isolation and loneliness have often been provided by health care service providers; however, housing may provide an additional avenue in which planners can make a contribution to this important issue.

\subsection{Research Objectives}

This research paper explores a number of key questions pertaining to social isolation, loneliness, social relationships and housing including:

- What are the implications of aging in place for social isolation and loneliness?

- Who is most vulnerable to social isolation and loneliness and what are the impacts?

- What are some housing options and their characteristics that may reduce social isolation and Ioneliness?

- What are the challenges to developing these options?

- Which of these options, if any, have the greatest potential?

\subsection{Outline of Paper}

This paper is presented in several sections. The first section provides an outline of the demographic shift that is the focus of this paper - the aging of the Canadian population. The potential implications of this shift and the preference to age in place are discussed. Also included is an overview of the underlying factors driving this shift and a number of Canadian social and demographic changes, which may have implications for older individuals. The second section discusses the concepts of social isolation and loneliness. These concepts are distinguished and risk factors for each are identified. The 
importance of social relationships and networks is also discussed with relation to these two concepts. The third section outlines four housing options, several of which are especially geared to older individuals. A description of each option is provided, including the general benefits and challenges, and opportunities for socialization and companionship. The fourth and final section discusses the key findings arising from the literature review and based on these considerations, the degree to which these four particular housing options may be able to help alleviate these issues. A number of recommended actions and areas for further research as they pertain to housing are provided.

\subsection{Methodology}

A review of the literature was completed to better understand the concepts of social isolation and Ioneliness and their consequences for older individuals. To provide context for this issue, social and demographic literature was also consulted to determine the underlying factors which may further contribute to social isolation or loneliness in the future. The review included literature from multiple fields of study. Key themes, including the characteristics of the types of individuals more vulnerable to these problems, were identified. The review also identified inconsistencies and limitations in the research and other issues that may have implications for planning. Furthermore, the review assessed how housing, in particular, is being addressed in the literature as a potential contributor or tool to alleviate these issues.

To better understand how housing might contribute to reducing social isolation and loneliness, four alternative housing options representing independent to semi-independent portions of the housing continuum were selected and researched. Characteristics of each option, particularly opportunities for socialization and companionship, are discussed. The discussion portion of the paper draws together key findings from the literature to help evaluate the strengths of these housing options to help combat social isolation and loneliness in older individuals. Recommended actions and areas for further research, as informed by the literature review and discussion, are provided. 


\subsection{BACKGROUND: CANADA'S AGING POPULATION}

Canada is currently undergoing a process of population aging. Population is contributing to both an increase in the absolute number of seniors and the proportion of seniors relative to other age cohorts. The population aging being experienced in Canada is not a standalone trend but an unprecedented global phenomenon.

\subsection{Aging in Canada: A Major Demographic Shift}

In Canada, 2011 marked the start to what is projected to be a surge in the seniors population, what has been referred to as a coming 'gray wave' or 'demographic time bomb'. The aging of the population is also underpinned by several additional trends, including declining birth rates, reduced mortality rates and longer life expectancies. Between 2011 and 2036, the number of seniors is projected to double from nearly 5.0 million to 10.4 million individuals, or from one in eight to one in four Canadians (Government of Canada, 2013a). While a number of definitions are used in the literature, for the purposes of this paper and consistent with Statistics Canada, a 'senior' is defined as an individual who is 65 years of age or older. The term 'senior' is also used interchangeably in this paper with 'older Canadian' and 'older individual'.

\subsubsection{The Baby Boomer Generation}

The aging of the Canadian population is largely attributed to Canada's largest generation, the Baby Boomer Generation. The Baby Boomer Generation is a cohort of individuals born between 1946 and 1965. The Baby Boom Generation also includes individuals born outside of Canada during this time frame who have since settled in Canada. This generation of Canadians was the product of the higher fertility rates that followed World War II and persisted until the mid-1960s. At its peak, 412,000 babies were being born each year (Statistics Canada, 2012a). More than sixty years later, this figure consistently exceeds more recent annual births numbers in the country.

The Baby Boomer Generation has had a lasting impact. It is argued that one of the greatest legacies of this generation may be attributed to the impact on the development of the suburbs (Schriener \& Kephart, 2010). This legacy is significant not only because of the way it has transformed the built form but because a significant number of seniors will be aging in place in these environments. Baby boomers also fueled demand for new housing and a range of amenities and services, such schools, health and social services (Hodge, 2008). As the baby boomers age in the coming decades, they will have a number 
of impacts. Future seniors are anticipated to differ significantly in their behaviors and attitudes, household and ethnic composition, economic security and access to informal family support (Hodge, 2008). Diversity represents a defining characteristic of the Baby Boomer Generation (Schriener \& Kephart, 2010). Compared to previous generations of seniors, the "generation now entering retirement is, on average, wealthier, better educated, and more active than previous generations of retirees" (CMHC, 2012, p. 5), having grown up and worked during times of relative prosperity. Future seniors are also anticipated to live longer than their predecessors.

Unlike previous generations of seniors it is believed that the baby boomers will differ significantly in what they demand from aging. As Harris (2012) suggests,

boomers are adamant that they do not want to live the way elderly people have in the past [...] after all, they were groundbreakers who brought the world rock ' $n$ ' roll, civil rights and environmental movements, Vietnam War protest and technological revolution. They expect to pioneer old age too.

Given the diversity of this cohort, forecasting future housing needs and preferences will be a challenge.

\subsubsection{Implications of an Aging Population}

The aging of the Canadian population is anticipated to have a number of consequences. Seniors provide significant benefits to their families and the community through mutual support, childcare, volunteerism, charitable giving and labour force participation. However, this population increase is anticipated to have implications for intergenerational equity in the form of intergenerational and intergenerational transfers, particularly income supports and health care (Baxter, Smerdon \& Ramlo, 2000). Some baby boomers will face a number of challenges as they transitions into old age, including a lack of retirement preparation, fewer private pensions and a lack of housing options (Novelli \& Workman, 2006, as cited in Novak, 2009). Furthermore, the Canadian Institute for Health Information estimates that population aging is also contributing to 0.6 percent and 2.3 percent annual increases in physician spending and long-term institutional care spending, respectively ( $\mathrm{ClHI}, 2011)$. While the seniors population currently accounts for only 14 percent of the population, approximately 44 percent of health care expenditures were spent on seniors in 2009 (2011). Similarly, the preference to age in place may result in a greater demand for and reliance on home care and home support services. Population aging will put pressure on informal supports networks, including family, friends and neighbours. In the United 
States, informal support has been estimated to have contributed an equivalent of $\$ 350$ billion dollars in services in 2006 (Gibson \& Houser, 2007, as cited in Novak, 2009). Historically, families have tended to provide significant support to aging family members; however, changing demographics and social trends will put additional strain on families. In some instances, adult children will be providing care to both their children and aging parents. These individuals, also known as the "sandwich generation", will face challenges in meeting the competing demands of work and family.

An aging population will also impact and shape patterns of housing needs, preferences and demands for services, and will create a greater need for home modifications, adaptations, innovative housing options (CMHC, 2008). However, the Canadian Mortgage and Housing Corporation (2008) suggests that not all communities are taking the steps and putting policies and plans into place help to prepare for these changes.

\subsection{Framework for Aging: Aging in Place}

Many seniors plan to continue to remain in their homes and communities for as long as possible. This strategy for aging is known as aging in place. Aging in place is a process by which individuals are facilitated in being able "to continue to live in their current home or familiar community for as long as possible even if their health changes" (CMHC, 2011, p. 114). An aging of the population will have significant implications for how cities, communities and neighbourhoods will need to be designed or modified and how services will be delivered. Closely related to an aging in place framework is the idea of creating senior-friendly communities, a concept widely promoted by the World Health Organization's Global Age-friendly Cities Guide (2007). The Guide outlines eight areas in which communities can be made more age friendly, including housing, outdoor spaces and buildings, transportation, social participation and employment, respect and social inclusion, civic participation, communication and information, and community support and health services. An increase in the number of older Canadians is challenging planners and policy makers to design environments and provide services to facilitate a successful aging of the population.

Research indicates that the vast majority of the population prefer to age in place. A Canadian Mortgage and Housing Corporation survey found that 85 percent of individuals 55 and above plan to remain in their current home for as long as possible, regardless of changes to their personal health (CMHC, 2008). A similar a survey conducted for the American Association of Retired Persons (AARP) involving 2,000 individuals aged 55 and above reports that 89 percent strongly agree or somewhat agree that they wish to remain in their current home as long as possible (Bayer \& Harper, 2000). The study also 
shows that even when care is needed, only 9 percent of respondents express a desire to relocate to an institutional facility. Households headed by a maintainer aged 65 and above are also less likely to move. Between 2001 and 2006, only 20 percent of these households moved compared with 44 percent for all other households (CMHC, 2011). Furthermore, the vast majority of seniors continue to live in private dwellings, rather than institutional housing. In 2011, 92.1 percent of seniors lived in private households, compared with 7.1 percent living in collective dwellings, such as nursing homes (Statistics Canada, 2012b). Also important is that more than half of Canada's oldest residents, those aged 90 and above, live in private households (56.5 percent), while over a quarter of those 90 and above live alone (28.7 percent) (Statistics Canada, 2012b).

For most people, aging in place includes finding alternatives to institutional living. Aging in place may involve home modifications, alternative housing options, advancements in gerontechnology and coordinated support (CMHC, 2011). For many, aging in place provides comfort, familiarity, safety, security and independence (Novak, 2009). As Hodge (2008) observes, “the importance of staying one's own home is heightened because of the security it represents, the memories it holds, and its proximity to friends and familiar neighbourhoods and their services" (p. 227).

\subsubsection{Challenges}

Many seniors will face challenges as they attempt to age in place at home or in their community. Hodge (2008) identifies a number of housing related challenges for seniors, including a current stock of housing that is poorly designed to meet changing needs, an aging housing stock and limited housing options for those seeking alternatives. In many locations, the housing stock has not been designed to meet the needs of older individuals. This housing, known as "Peter Pan" housing, has essentially been designed for people who never grow old (Pynoos et al., 2008). Often located in suburban areas and disconnected from amenities and public transit, much of this housing has been "designed for busy people who work during the week, want to get home as fast as possible, and have their own vehicles to pursue personal interests and activities outside of the home" (CMHC, 2008, p. 6). Some seniors will also face challenges in undertaking home modifications due to a lack of financial resources, knowledge or ability to do the modifications (Pynoos et al., 2008). However, despite these challenges, the increase in the seniors population will put pressure on costly institutional facilities, making aging in place with the proper supports a practical and desirable alternative.

Seniors residing in small towns and rural areas may face additional challenges where services are more dispersed, the construction industry for seniors housing is smaller and where both rental 
options and transportation are limited (Federal/Provincial/Territorial Ministers Responsible for Seniors, 2007). Options for semi-independent housing are often especially limited (Hallman \& Joseph, 1997). Furthermore, the availability of family support may be reduced as younger residents seeking employment opportunities relocate to larger urban centres.

\subsubsection{Emotional Well-being and Aging in Place}

For some seniors, aging will be accompanied by a loss of family, friends and other contacts as well as changes in health, which may reduce mobility, make it difficult to maintain relationships and reduce opportunities to participate in activities. For these seniors, aging in place may contribute to social isolation and loneliness, decreasing quality of life and having implications for health and well-being. As a result, remaining in the home, the preferred option for many seniors, raises a number of issues. Demographic trends suggest that an increasing number of older Canadians will likely find themselves living alone, many with smaller families and social networks to rely on for support. The lack of close contacts will not only impact the provision of informal support but will also potentially result in a greater risk of becoming socially isolated and experiencing subjective feelings of loneliness.

The impact of aging in place in an emotionally and social supportive environment has received relatively little attention in comparison to aging in place with the appropriate modifications to support one's physical environment needs. Addressing social isolation and loneliness are key elements of a comprehensive strategy for aging in place.

\subsection{Canadian Context: Social and Demographic Trends}

The aging of the Canadian population is also occurring alongside a number of other demographic and socio-economic trends, which will affect the ability of future seniors to age in place. These trends represent a marked departure from social patterns characterizing previous generations of seniors and will have implications for housing and support.

\subsubsection{More People Living Alone and in Smaller Households}

In recent years, there has been an increasing trend towards households consisting of individuals living alone. In 2011, for the first time the percentage of single person households exceeded the number of households with children (27.6 percent vs. 26.5 percent) (Statistics Canada, 2013). In 2011, 24.8 percent of seniors reported living alone, increasing to 31.8 percent for those 85 and above. While more than half (56.4 percent) of seniors lived in a couple (with a married spouse or common-law partner), due 
to the loss of a spouse or partner, this proportion generally decreases with increasing age (Statistics Canada, 2013) (Figure 1). In 2011, only 21.9 percent of all seniors reported living a couple, with rates varying significantly between men (46.2 percent) and women (10.4 percent) (Statistics Canada, 2012b).

Living arrangements have important implications for care, support and companionship. Individuals who do not live with others tend to have more unmet needs, such as those pertaining to help with daily activities (La Plante et al., 2004, as cited in Novak, 2009).

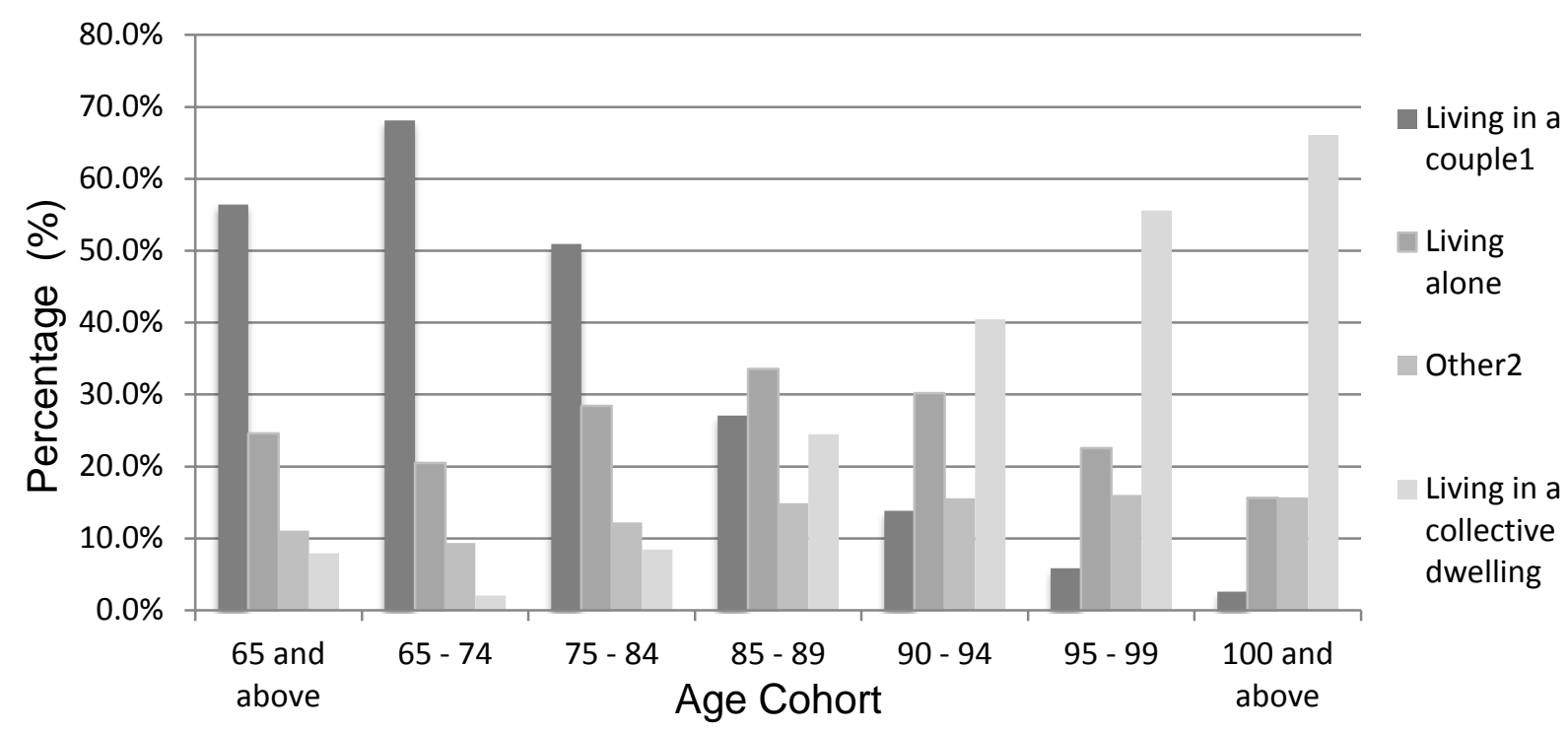

Figure 1. Living arrangements of Canadian seniors, 2011. Note: Data from, Statistics Canada, Census of Population, 2011.

1 Includes married spouses and common-law partners; ${ }^{2}$ Includes seniors who are lone parents, living with other relatives or non-relatives or adult children living with parents

Changes in family size and composition are another significant trend. For the baby boomers, the high fertility rates that characterized the late 1940s through the early 1960 s have not been matched by subsequent generations, leading to smaller households with fewer children. The average Canadian household size has decreased from 3.7 persons in 1971 to 2.5 persons in 2006 (Government of Canada, 2013b), while the average number of children per family has decreased from 2.7 in 1961 to 1.9 in 2011 (Statistics Canada, 2012c).

\subsubsection{More People Living Longer, Healthier Lifestyles}

Today, Canadian seniors are living longer, healthier lives compared to past generations of seniors. Life expectancies are projected to continue to increase significantly over the next two decades, which will have implications for the numbers of older seniors and for housing and aging in place. In 2006, 
the average life expectancy was 82.9 years for women and 78.2 years for men (Statistics Canada, 2010a). However, Statistics Canada predicts that by 2036, life expectancies will have risen 4.4 years for women and 5.8 years for men (2010a). Longer life expectancies will result in larger numbers of seniors living to old age ( 75 to 84 years) and very old age ( 85 and above).

\subsubsection{Changing Social and Support Networks}

Holt-Lunstad, Smith and Layton (2010) suggest that there has been a decrease in the quality and number of social relationships in recent years. The 2003 General Social Survey undertaken by Statistics Canada found that 18 percent of seniors over the age of 75 report having no close friends and that in the previous month, 75 percent of seniors did not meet someone new (Turcotte \& Schellenberg, 2006). Furthermore, the increasing mobility of individuals today may create families where members are separated by greater distances, reducing the availability of support. In the future, services that have generally been provided by family may become less available, leading more seniors to rely on services provided by governments, non-profit organizations and volunteers (Hodge, 2008). Statistics Canada's 2007 General Social Survey indicates that approximately one-third of caregivers to seniors were neighbours (5 percent), friends (14 percent) or extended family (11 percent) (Cranswick \& Dosman, 2008). While the impact of these trends on the availability of support is unknown, they will likely impact the availability of informal support and care and social networks.

\subsubsection{Summary}

Social and demographic trends suggest that in the future, many seniors may have less informal support than previous generations of seniors. The Canadian Mortgage and Housing Corporation (2008) suggests that because "children are in shorter supply for tomorrow's seniors and are more likely to be working" and that "[seniors] may have less informal help from family members and close friends than previous generations" (p. 7). An increase in female workforce participation may also reduce the availability of support, as daughters have primarily provided a significant portion of informal care to aging parents. These trends will be compounded by the changes and losses in social relationships and networks often associated with advancing age. These trends may contribute to increasing social isolation and loneliness among some seniors. 


\subsection{SOCIAL ISOLATION AND LONELINESS IN OLDER ADULTS}

Changing demographics and family structures are prompting worries that there may be an increase in the number of older individuals increasingly vulnerable to becoming socially isolated (Weeks, 2013; Perlman, 2004). Citing a number of researchers, Kobayashi (2011) indicates that "[o]lder adults who live alone and have small social networks are often believed to be "at risk" of or vulnerable to decreased emotional well-being by virtue of their limited social connections" (p. 2).

Social isolation and loneliness have received attention in the fields of gerontology and health. However, as Australian researchers Franklin and Tranter (2011) suggest, "there is practically no evidence of housing policy that addresses [loneliness] explicitly or directly" (p. 1). Social isolation and loneliness have been identified in several documents as important issues for seniors. In 2003 , social isolation was identified as a key issue for future policy development by the Canadian Federal, Provincial and Territorial Task Force on Seniors (Cloutier-Fischer \& Kobayashi, 2009). Social isolation and loneliness are also identified in the 2006 Healthy Aging in Canada: A New Vision, A Vital Investment background paper prepared for the Federal, Provincial and Territorial Committee of Officials (Seniors).

Despite the perception that loneliness strikes a large proportion of the population, many studies concur on the fact that most older people are neither lonely nor socially isolated (Victor et al., 2000). However, for those individuals affected, being socially isolated and/or experiencing loneliness may have far-reaching consequences, including contributing to negative outcomes for both health and well-being.

\subsection{The Relationship between Social Isolation and Loneliness}

Social isolation and loneliness are two closely related concepts, yet the exact relationship between the two is not well understood. A number of researchers comment that despite this gap in understanding, many of the same factors are understood to influence both (de Jong-Gierveld, 1998; Wenger \& Burholt, 2004).

\subsubsection{Social Isolation}

Social isolation refers to an objective experience characterized by a "reduced support network size and low frequency of social contacts" (Cloutier-Fischer, Kobayashi \& Smith, 2011, p. 407). Small social networks have been associated with an increased risk for physical and emotional vulnerability and socially isolation (2011). Social isolation is believed to contribute to the development of loneliness; however, not all individuals who are socially isolated are lonely. In some instances, social isolation, or 
solitude as it referred to in this instance, may be considered beneficial or even desired. Some individuals have always lived relatively solitary lives and despite limited socialization and small networks, are quite content with their social networks (Cloutier-Fischer, Kobayashi \& Smith, 2011).

\subsubsection{Loneliness}

In contrast to social isolation, loneliness is a subjective personal experience. Loneliness has been described as "an unwelcome feeling of lack or loss of companionship, the negative, unpleasant aspects of missing certain relationships as well as missing a certain level of quality in one's relationships" (de Jong-Gierveld, 1998, p. 73). Most researchers agree that loneliness does not simply reflect a lack of relationships but signifies a perceived deficiency between the relationships that an individual has and the relationships that the individual desires. In relation to social isolation, Franklin and Tranter (2011) describe loneliness as "the negative emotional experience of social isolation" (p. 2), while Havens and Hall (1999) similarly describe loneliness as "negatively perceived social isolation" (para. 4).

Until the 1970s, relatively little research on loneliness and its effects had been undertaken. Researchers concerned with loneliness note the stigma that is often associated with the experience (de Jong-Gierveld, 1998; Franklin \& Tranter, 2011; Perlman, 2004; Victor et al., 2000). Weiss' 1973 book, Loneliness: The Experience of Emotional and Social Isolation represents a landmark exploration in this area. In the decades that followed its publication, a large number of studies have attempted to explore various aspects and nuances between loneliness and social isolation. Weiss (1973) identifies two types of loneliness: emotional loneliness and social loneliness. Emotional loneliness refers to the "absence of a close emotional attachment", such as a partner, spouse or other confidant (p. 19). Social loneliness, on the other hand, is described as "the absence of an engaging social network" (p. 19). Unlike emotional loneliness, only social loneliness can potentially be ameliorated by increasing social contacts (1973). While some studies on loneliness attempt to differentiate between these two types, many tend to use a more generic measure which incorporates elements representative of both types (Piquart \& Sorensen, 2001, as cited in Perlman, 2004; van Tilburg, Havens \& de Jong-Gierveld, 2002). While the exact cause of Ioneliness remains unknown, Cacioppo and Patrick (2008) argue that loneliness has biological or evolutionary roots and may have evolved similar to the evolution of physical pain as a means of protecting the individual from danger, particularly the dangers associated with becoming isolated from others. Although often associated with the elderly, loneliness is not an experience confined to older individuals. Significant research on loneliness involving adolescents and young adults has been completed, which has 
led some researchers to comment that there has been a disproportionate research effort directed towards to these groups (Perlman, 2004).

Literature on the prevalence of loneliness among older individuals suggests that, while not epidemic, a proportion of the seniors population may be affected. A study completed by Statistics Canada using data from the 2008/2009 Canadian Community Health Survey (CCHS) - Healthy Aging found that approximately 20 percent of seniors reported subjective loneliness (Gilmour, 2012). Other studies report a range of rates, including 16.3 percent (Paúl \& Ribeiro, 2009), 38 percent (Newall et al., 2009), 39 percent (Roustasalo et al., 2006) and 45 percent (Havens et al., 2004). Some of the variability in the rates of incidence may be attributed to the use of different definitions and approaches to measurement used to approximate the incidence of loneliness. While some researchers suggest loneliness is a pervasive phenomenon (van Tilburg, Havens \& de Jong-Gierveld, 2002; Weiss, 1973), others argue that its prevalence may be somewhat overestimated (Dykstra, 2009). Furthermore, while a significant portion of the population report being neither socially isolated nor lonely, researchers believe that attempts to measure loneliness may underreport its incidence due to the stigma that is associated (de Jong-Gierveld, 1998; Perlman, 2004; Victor et al., 2000).

\subsection{Consequences of Social Isolation and Loneliness}

The World Health Organization (WHO) (2013) indicates that "loneliness, social isolation and social exclusion are important social determinants and risk factors for ill health among older people" (para. 10). The literature suggests that for some individuals, social isolation and loneliness may be associated with a number of consequences. Being socially isolated may also contribute to depression, feelings of loneliness, inappropriate use of health care services, premature institutionalization and death (Hall, 2004). A study by Holt-Lunstad, Smith and Layton (2010) indicates that social relationships can have a significant bearing on health, particularly one's risk of mortality. In their meta-analysis of 148 studies including more than 300,000 participants, the authors show that among participants, stronger social relationships were associated with a 50 percent increase in the likelihood of survival. Moreover, the authors conclude that "the magnitude of the effect is comparable with quitting smoking and it exceeds many well-known risk factors for mortality", such as obesity or physical inactivity (p. 14). At a community scale, social isolation may also contribute to reduced social cohesion, ageism and a lack of engagement with the broader community (Hall, 2004). 
Similarly, a number of studies have found an association between greater loneliness and an increased likelihood of mortality (Jylha, 2004; Peissinotto, Stijacic \& Covinsky, 2012). Peissinotto, Stijacic and Covinsky's (2012) study of 1,064 adults aged 60 and above found an increased risk of death for participants reporting being lonely within the six year study period. 43 percent of participants responded that they were sometimes lonely, which corresponded to a 45 percent greater likelihood of dying. Their results also indicate that lonely individuals are more likely to experience decline in activities of daily living (ADL), reduced mobility, difficulties performing upper extremity tasks and difficulty climbing. Peters (2004) also refers to several studies indicating that loneliness has been found to be associated with a number of conditions, including diabetes, heart disease, respiratory conditions, ulcers and abdominal and lower back pain. A study by Cacioppo et al. (2002) reports higher cardiovascular activation (elevated blood pressure) and poorer sleep quality among those reporting being lonely. Loneliness has also been associated with a greater risk of being admitted to institutional care. Russell et al.'s (1997) study involving 3,000 lowans over a period of four years found "extreme loneliness [to be] a significant predictor of admission to a nursing home among rural men and women" (p. 584). The study also found that those reporting higher levels of loneliness were less likely to be continuing to reside in the community after four years. Some researchers further suggest that lonely individuals contribute to an inappropriate use of health care services (Cloutier-Fisher \& Kobayashi, 2009).

The studies presented suggest that individuals who are socially isolated or who experience loneliness may be more vulnerable to a number of negative and well-being health outcomes, underscoring the importance of addressing this important issue.

\subsection{Who is Socially Isolated or Lonely? Risk Factors}

Significant research has been undertaken to better understand the potential risk factors for social isolation and loneliness. Identifying the characteristics of individuals or groups that may be more likely to become social isolated and lonely is critical. Factors such as personal background, culture, age, gender, marital status, living alone, health and disability, socio-economic status and relationships have been explored to determine whether these factors can help predict social isolation and loneliness. Also important, Havens and Hall (1999) suggest that many of these risk factors may have additive effects, with certain individuals being more vulnerable because of compounding factors. 


\subsubsection{Personal Background, Social and Cultural Factors}

Susceptibility to loneliness is also impacted by personal factors, which explains why some individuals experience more or less loneliness than others in similar situations. Peplau and Perlman's Discrepancy Model explains why some individuals experience loneliness differently than others. The Discrepancy Model indicates that the prevalence of loneliness is not entirely based on a lack of contacts but rather represents a mismatch between an individual's actual social relationships and the social relationships that they desire (Perlman \& Peplau, 1981, as cited in Perlman, 2004). Additional factors, such as causal beliefs or those pertaining to self-perception of the ability to make new friends have also been identified as factors contributing to loneliness (Newall et al., 2009).

As Jylha (2004) observes, loneliness is not only an individual or personal phenomenon but also a cultural one. The experience of loneliness is, in part, a product of social and cultural norms about acceptable or ideal numbers of relationships (de Jong-Gierveld, 1998). Dykstra (2009) indicates that minimal standards for social contact are determined by two factors, "the cultural value system in a society and the amount of social contacts to which people are normally accustomed" (p. 95). A number of studies have explored the effect of culture on loneliness. For example, studies demonstrate that the incidence of loneliness varies between European countries, with greater prevalence being reported in southern European countries as opposed to northern countries (Jylha \& Jokela, 1990, as cited in Jylha, 2004). It has been hypothesized that greater loneliness should be expected in countries with more individualistic tendencies; however, studies find that the incidence of loneliness is actually greater in countries where living alone is less common (Goodwin, Cook \& Yung, 2001; Jylha \& Jokela, 1990, as cited in Jylha, 2004).

\subsubsection{Age and Gender}

Research on loneliness finds that its prevalence among older adults generally increases with age (Goodwin, Cook \& Yung, 2001; Havens et al., 2004; Jylha, 2004; van Tilburg, Havens \& de Jong-Gierveld, 2002; Wenger \& Burholt, 2004). However, cross-sectional and longitudinal studies by Jylha (2004) suggest that "Ioneliness does increase with age, not because of age per se, but because of increasing disability and decreasing social integration" (p.157). The causes of social isolation and loneliness may be in part attributed to what gerontologists refer to as normative age-graded events. Normative age-graded events are those that tend to occur at particular points in the lifecycle, such as marriage, retirement or widowhood. Advanced age is often considered a time of many events and changes, including losses across one's social network and declining health, both of which have implications for remaining socially 
engaged. As Havens and Hall (2001, as cited in Havens et al., 2004, p. 130) comment, “[s]ocial isolation and loneliness may result as a consequence of the reduction in social contact following retirement, the death of family members and friends, residential relocation, or the increased risk of mortality and health problems associated with growing older".

An analysis by Dykstra (2009) of several studies measuring loneliness across different age cohorts suggests that the incidence of loneliness is highest among youth and young adults, decreases among middle aged adults and increases with advancing age (Figure 2). However, other studies suggest that loneliness may only be common among the very old (Dykstra, 2009; Jylha, 2004; Victor et al., 2000).

Several studies also suggest that social isolation and loneliness are generally more common among women than men (Cloutier \& Kobayashi, 2009; Gilmour, 2012; Havens et al., 2004; Jylha, 2004; van Tilburg, Havens \& de Jong-Gierveld, 2002; WHO, 2013). This is often attributed to longer life expectancies, contributing to a greater likelihood that a woman will live alone, outlive a spouse and encounter increasing and multiple health issues (Havens \& Hall, 1999). However, these findings conflict with other studies that suggest loneliness may be more prevalent among men (Mullins, 1996). Men are suggested to have a more difficult time making new friends, becoming involved in new activities and generally adjusting to changing roles, such as assuming greater household responsibilities following the death of a partner (Gilmour, 2012; Hall, Havens \& Sylvester, 2003). While the literature suggests that both men and women are affected by social isolation and loneliness, the potential causes are likely different.

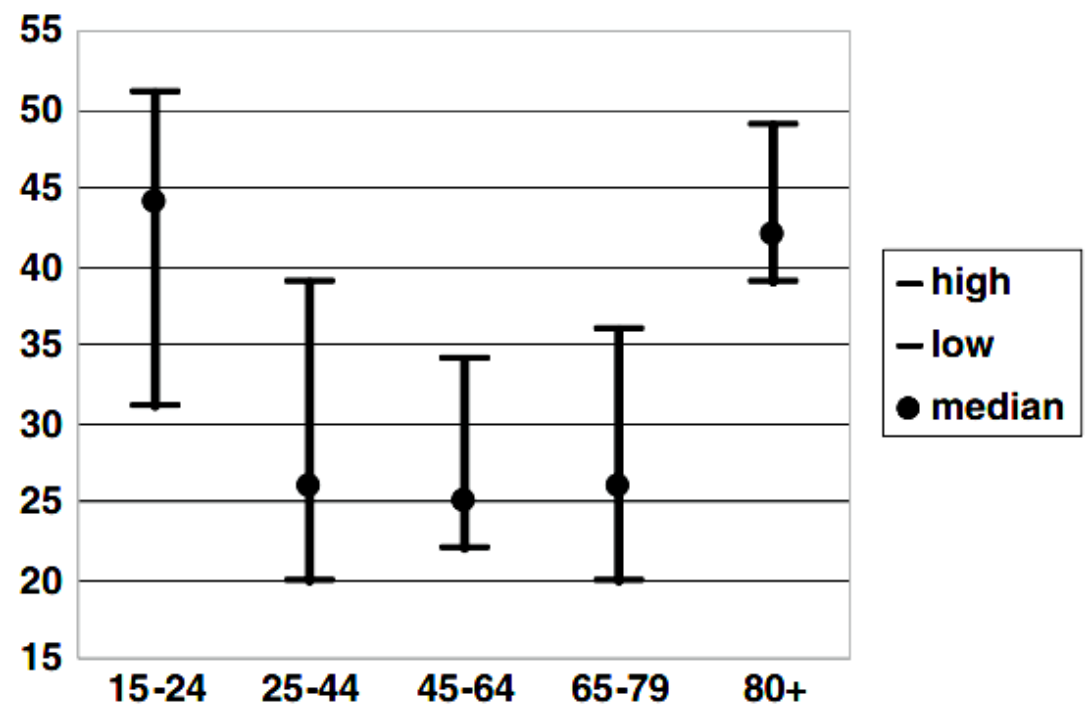

Figure 2. Reported loneliness by age. Note: From, Dykstra, 2009. 


\subsubsection{Health and Disability}

Poor health appears to be an important factor associated with an increased risk for becoming socially isolated and lonely (Cloutier-Fisher \& Kobayashi, 2009; Wenger \& Burholt, 2004). However, like many of the factors discussed, the direction of causality is not known, that is, whether being socially isolated or lonely contributes to poor health, or whether those who are already in poor health are more prone to becoming socially isolated or lonely.

Those reporting poorer self-perception of health also consistently report greater loneliness (Franklin \& Tranter, 2011; Heylen, 2010; Mullins, 1996; Paũl \& Riberio, 2009; Roustasalo et al., 2009). Similarly, declining cognitive health has also been identified as a risk factor for loneliness (Havens et al., 2004; Paũl \& Riberio, 2009) as is reporting disability (Gilmour, 2012). Declining health creates barriers to participation, making it difficult to establish new and maintain existing relationships. Physical impairments, including a loss or impairment in vision, sight or hearing, may be embarrassing and make communication with others a challenge (Hall, Havens \& Sylvester, 2003).

\subsubsection{Socioeconomic Status}

The impact of socioeconomic status on loneliness has been explored. A study by Mullins (1996) reports greater loneliness among older adults who perceived themselves as having an inadequate economic situation.

\subsubsection{Living Arrangements and Living Alone}

A number of studies explore the relationship between widowhood and social isolation and Ioneliness (Cloutier \& Kobayashi, 2011; Hall, 2004; Wenger \& Burholt, 2004). Widowhood has been found to be a strong predictor of loneliness (Havens et al., 2004; Paũl \& Riberio, 2009; Roustasalo et al., 2009), with the risk of loneliness generally decreasing when a partner is present (van Tilburg, Havens \& de Jong-Gierveld, 2002). A partner may provide greater opportunities for socialization. However, in other situations, caregiving responsibilities may reduce social contact and contribute to social isolation among seniors providing care to another person (Hall \& Havens, 1999). Other studies explore the impact of seniors residing with family. A study by Wenger and Burholt (2004) reports higher levels of loneliness among older individuals who reside in the home of a child.

Research suggests that living alone is an important predictor of social isolation and loneliness. Social trends indicate that more individuals across all age cohorts are living alone. Living alone has been found to be associated with social isolation and loneliness (Hall, 2004; Havens et al., 2004; Wenger \& 
Burholt, 2004). Living alone may reduce opportunities for contact outside the home or the availability of another person to go out with, which may contribute to social loneliness. However, as previously mentioned, it is worth noting that not every individual who lives alone considers themselves lonely.

\subsubsection{Location, Moves and Housing}

A number of studies explore whether seniors living in urban or rural locations are more vulnerable to becoming socially isolated or lonely. The less personal nature of urban areas has been suggested to contribute to a higher risk of Ioneliness; however, Mullins (1996) finds no relationships between social isolation and loneliness for either urban or rural locations. Other studies report inconclusive findings (Havens et al., 2004). Several studies also explore the impact of a move on social isolation and loneliness. Moves have been associated with an increase in both social isolation and loneliness (Havens \& Hall, 1999; Victor et al., 2000). Both social isolation and loneliness have also been associated with residing in or making a move to a nursing home (BC Ministry of Health, 2004; Victor et al., 2000).

In one of the few studies to specifically address housing, research by Franklin and Tranter (2011) on Australian seniors also finds that the prevalence of loneliness is higher among seniors those residing in rental housing and public housing.

\subsubsection{Social Relationships and Networks}

Social relationships are an important element of successful aging, good health and well-being (Gilmour, 2012) and social integration and participation are considered important indicators of productive aging (de Jong-Gierveld, 1998). Using data from the 2008/09 Canadian Community Health Survey (CCHS) - Healthy Aging, a study of over 30,000 Canadians aged 45 and above, Gilmour (2012) finds that a greater frequency of social activities is associated with a greater likelihood of reporting positive selfperceived health and a reduced likelihood of reporting loneliness. Furthermore, a number of studies attempt to determine the extent to which relationships with family and friends, quantity of contacts (social network size), quality (satisfaction and fulfillment with contacts and relationships) and frequency of contact are important to older individuals. An understanding of the types of relationships beneficial to older individuals may help inform a discussion on whether new social relationships can be easily fostered through alternative housing and living arrangements.

Unsurprisingly, a number of researchers report a higher likelihood of loneliness among those with fewer social ties (Cacioppo \& Patrick, 2008; Dykstra, 1990). However, in a study of older individuals with small social networks, Cloutier-Fisher and Kobayashi (2009) report that even "small social networks can 
protect older adults from social isolation and loneliness" (p. 409). The importance of frequency of contact has also been explored. Heylen (2010) indicates that a "higher frequency of contact with non-household members [was] associated with less social loneliness" (p. 1187). Heylen also argues that the number of social relationships and frequency of contact has an impact on loneliness, irrespective of the preferences or deficiencies of these contacts.

Other studies explore the effect of relationships with family and friends on loneliness. Some studies suggest that a lack of children or grandchildren is actually associated with less loneliness (Mullins, Johnson \& Anderson, 1987). Their study finds that relationships with friends and neighbours may be more important for reducing loneliness. Similarly, Dysktra (1990) finds that where individuals report a high proportion of family or kin relationships, loneliness among participants was generally greater. Mullins (1996) finds that a lack of friends to be a predictor of loneliness. Together, these suggest that relationships with peers may be especially important for some seniors. Some researchers also suggest that older individuals prefer the company of their peers due to the voluntary nature of these relationships (Mullins, Johnson \& Anderson, 1987).

Conversely, Victor et al. (2000) points to a number of studies providing conflicting evidence as to the effect of adult children on loneliness. Research by Mullins (1996) suggests that children and grandchildren may have a protective effect in preventing loneliness. Mullins (1996) reports a lack of children a risk factor for loneliness. Mullins et al. (1989, as cited in Mullins, 1996, para. 12) finds that "persons with more children residing nearby were less likely to be lonely than those with fewer proximate children". Similarly, living near adult children is suggested to prevent loneliness, although the authors also report that seniors living in the home of a child may actually report higher levels of loneliness (Wenger \& Burholt, 2004).

The quality of relationships is also believed to be of key importance in reducing loneliness. Troublingly, research by Mellor et al. (2008, as cited in Franklin \& Tranter, 2011, p. 3) suggests that "people living with others have just as many unmet needs and are just as lonely as people living alone. In other words, what are missing in a widespread sense, are qualitatively emotionally satisfying relationships, not relationships per se". This suggests that increasing the number social contacts may not be sufficient to alleviate loneliness for some seniors (Roustasalo et al., 2006). Similarly, several studies also conclude that the quality of relationships is likely more important than their quantity or frequency (Cacioppo \& Patrick, 2008; Roustasalo et al., 2009). These researchers, among others, conclude that dissatisfaction with existing relationships, including unfulfilled expectations of family or friends, are important risk factors for loneliness. An unfulfilled desire for greater contact with family is also found to 
be associated with greater loneliness (Cacioppo \& Patrick, 2008; Franklin \& Tranter, 2011; Mullins, Johnson \& Anderson, 1987). These studies support the discrepancy model of loneliness, which demonstrates that loneliness represents, at least in part, a mismatch between actual and desired relationships.

The ability to develop and maintain relationships is also dependent on personal capacity and interest. As a number of researchers suggest, there is a need to explore the importance of social relationships from a life course perspective that takes into account these personal factors, backgrounds and histories (Koropeckyj-Cox, 1998).

\subsubsection{Interventions: Reducing Social Isolation and Loneliness}

Research on social isolation and loneliness is often grounded in the fields of gerontology and health and interventions to address these issues have commonly been designed and delivered by health care service providers and agencies. A number of social programs, including outreach, friendly visits, congregate meals, volunteer recruitment and transportation to activities have been developed and to provide connections between individuals and the community.

Housing appears to be very infrequently mentioned as a possible intervention. Perlman, Gerson and Spinner (1978, as cited in Campbell \& Novak, 2000) suggests that loneliness can be reduced by helping seniors maintain their existing contacts through transportation, housing and a number of other elements. Havens et al. (2004) suggests that seniors may benefit from a greater number of housing options, including age-segregated housing and communities. The authors also suggest that housing should help "fosters social interaction and [encourage] socialization" (p. 138).

Some researchers also argue that relationships alone are not sufficient to alleviate loneliness. Increasingly, quality relationships that can address the subjective mismatch between actual and desired relationships is crucial. Understanding the risk factors for loneliness and social isolation, as well as the impact of social relationships on the health and well-being of older individuals is essential for creating policies that address not only the physical but also the emotional needs of individuals as they age.

\subsubsection{Literature Limitations}

There is a significant body literature which explores issues of social isolation, loneliness, social relationships and number of other closely related concepts. However, the literature must be interpreted with some caution. 
Consistency of results is dependent on how social isolation and loneliness are defined and measured. Defining social isolation is challenged by the use of different criteria to determine whether an individual is socially isolated. Due to its subjective nature, loneliness can be especially difficult to define. However, much of the literature is consistent in several regards, that loneliness is subjective, is an unpleasant or distressing experience, and represents a discrepancy (West, Kellner \& Moore, 1986). The literature further identifies two general types of loneliness, which are not consistently differentiated in the literature. The literature suggests that because social loneliness and emotional loneliness have different root causes, differentiating the two is especially important given that each likely responds very differently to different interventions (Roustasalo et al., 2006; van Tilburg, Havens \& de Jong-Gierveld, 2002; Weiss, 1973).

A number of issues also arise when measuring social isolation and loneliness. The subjective nature of loneliness makes it especially difficult to measure. A number of approaches are identified in the literature, including direct methods that include asking participants if they are lonely and less direct or aggregate methods that attempt to approximate loneliness using a scale that incorporates a range of questions acting as a proxy. As indicated previously, the incidence of loneliness varies considerably, which likely reflects the use of different methodologies. Furthermore, a number of studies indicate that cultural norms and values may have an impact on social isolation and loneliness, indicating that caution must be exercised when applying findings from other locations (Jylha, 2004).

The literature review identified a number of variables which may make an individual more vulnerable or a greater risk for social isolation or loneliness. However, there are complex effects for many of these variables and the direction of causality is rarely well understood. Whether these factors are directly or indirectly affecting or affected by social isolation or loneliness remains unclear. The unknown direction of causality is problematic for planners, policy makers and others attempting to develop interventions to respond to these issues (BC Ministry of Health, 2004).

A review of the literature on social isolation and loneliness also indicates that there is relatively little mention of how housing, in particular, may help specifically address this problem. Housing is often acknowledged by researchers as being integral to these issues; however, the details of how housing can respond are rarely elaborated upon. 


\subsection{HOUSING OPTIONS TO RESPOND TO SOCIAL ISOLATION AND LONELINESS}

As the population ages, many older Canadians will begin to re-evaluate their housing needs. Policies that encourage aging in place can help seniors live longer and more safely in their homes or communities. Providing a range of housing options is seen as critical to creating livable, complete communities that foster a high quality of life for all members of society. At the same time, social and demographic trends suggest that in the future, many more seniors will be living in housing that is not only inadequate in meeting their physical needs but also possibly inadequate in terms of providing for their social and emotional needs.

The Canadian Mortgage and Housing Corporation (n.d.a.) indicates that housing standards are composed of three key elements that refer to housing cost (affordability), the need for repairs (adequacy) and the minimum number of bedrooms (suitability). However, these standards primarily address the physical and economic aspects of housing and do not address the emotional or social suitability aspects. As Novak (2009) argues, "[h]ousing can mean simply a roof and four walls, or it can mean a setting that enhances a person's well-being" (p. 280).

A number of social programs, including outreach, friendly visits and transportation to activities have been created to address this deficiency and to provide connections between housebound individuals and the community. However, for some seniors, these programs may be an inadequate substitute for daily companionship. While housing is only one element of a well-rounded aging in place framework, individuals spend a significant portion of their time in their homes, highlighting the importance of a supportive home environment and reinforcing the importance of planning communities that foster opportunities for socialization and engagement.

The remainder of this paper explores a number of housing and living arrangements along a broader housing continuum. The characteristics of these housing alternatives, including the potential of each to facilitate new opportunities for socialization among older individuals, are discussed.

\subsection{Continuum of Housing}

Researchers have long emphasized the need for a number of alternative housing options to meet the diverse needs of a diverse aging population (Ministry of Municipal Affairs and Housing, 2011; Pynoos et al., 2008). Seniors housing is often presented along a spectrum or continuum, premised on the idea 
that as individuals age, their health and support needs will change and may prompt a response in their housing needs. In some instances, this change can be met with alterations to existing housing or may require new housing altogether. Brink (1985) identifies a range of housing options, generally fitting into three categories along the continuum: independent, semi-dependent and dependent (Table 1). Independent housing options are appropriate for seniors who are essentially independent and require minimal regular assistance. On the opposite end of the spectrum, dependent housing may be appropriate for seniors with high levels of impairment. Semi-dependent housing options are designed for seniors requiring intermediate levels of care and assistance to continue to live independently. Seniors housing may include age-segregated, age-integrated (multigenerational), private, collective or shared options.

Table 1. Housing Continuum

\begin{tabular}{lll}
\hline \multicolumn{1}{c}{ Independent Options } & \multicolumn{1}{c}{$\begin{array}{c}\text { Supported Independent } \\
\text { Options }\end{array}$} & Dependent Living Options \\
\hline Single family houses & Single family & Nursing homes \\
Rental apartments & Rental & Extended care \\
Townhouses & Condo & Hospital geriatric care \\
Condominiums & Coops & \\
Cooperative & Live-in housekeeper & \\
Mobile homes & Home sharing & \\
Shared (home share, & Granny flats & \\
boarders) & Living with family & \\
Cottages & Boarding houses & \\
Retirement community & Retirement hotels & \\
Includes senior geared & Homes for aged & \\
versions of these options & Group homes & \\
& Congregate housing & \\
& *with home care from & \\
& family or community & \\
\hline
\end{tabular}

Note: Adapted from, Brink, 1985.

Four housing options are described below. These options were selected because each offers some potential for companionship or support (from friends, family or others), is designed or promoted primarily to seniors and is a less traditional option to aging in place. Selected options include cohousing, congregate housing, home sharing and garden suites. These options include those favoring the independent and semi-independent portions of the continuum. Housing options situated along the more supportive or dependent portions of the spectrum are generally not considered preferred options to aging in place. 


\subsubsection{Cohousing}

The cohousing model is a form of housing that emerged in Denmark in the 1960s and later in Canada in the 1980s. Cohousing is based on principles of collective planning and decision making, mutual support and sense of community. Most cohousing developments were initially created to facilitate intergenerational living, with age-segregated options developing later. Cohousing developments typically include significant shared spaces, such as a common house, communal kitchen, workspaces, workshops and gardens (CMHC, n.d.b). Each household maintains a private unit, complete with all the amenities associated with a traditional detached home. Cohousing developments range in size, with 15 to 30 units per development being standard (Durrett, 2009). The cohousing model is characterized by six main principles identified by Durrett (2009). These include having a participatory process, deliberate neighbourhood design, extensive common facilities, complete resident management, non-hierarchal structure and not being income-generating. Cohousing developments are often privately owned; however, rental options are possible. Cohousing offers residents a number of financial, environmental and social benefits. Individual units are generally smaller than traditional homes (about 60 percent the size) and consume approximately 30 percent less land, making them less expensive than housing in traditional suburban communities (Durrett, 2009). Cohousing may actually allow residents to remain in their home for 8 to 10 years longer (Canadian Senior Cohousing, n.d.a.).

'Seniors cohousing', a variation on the original model, has only recently emerged. Seniors cohousing was developed in response to the deficiencies identified by residents of cohousing as they aged. Seniors cohousing was developed in the 1990s and while similar to age-integrated cohousing, this model includes additional principles such as 'co-care'. Co-care is the voluntary provision or receipt of assistance with tasks such as running errands, transportation or general support (Canadian Senior Cohousing, n.d.b). Co-care represents "a grassroots model of neighbourly mutual support that can help reduce social isolation and promote positive, active aging" (Canadian Senior Cohousing, n.d.b., para. 2).

Unlike other housing options, residents of cohousing often select this form of housing because of its potential for creating greater community ties. Researchers suggest that while cohousing residents are often very diverse, many share similar attitudes and values towards community, which can help enhance social interactions (Williams, 2005). In a longitudinal study completed between 2006 to 2009 of a seniors cohousing project in Virginia, the researchers report that the primarily reason for choosing cohousing among the 33 of participants was a desire for a greater sense of community (Glass, 2009). This was followed closely by mutual support. Glass (2009) reports that 80 percent of participants surveyed indicated that they would be very likely to ask other residents for home/personal care help due 
to a health issue, compared with approximately a third for family. This suggests somewhat strong relationships between community members.

Cohousing also provides opportunities for social events and activities. Residents of cohousing developments may arrange and participate in shared dinners, social events and other activities. The frequency and type of events varies between communities. However, one survey of Dutch cohousing residents found that many residents prefer gatherings, such as meals, social events or trips, only a few times per year and that very few members desire activities on a very frequent or daily basis (Singelensberg, 1993, as cited in Choi, 2004). The study concludes that residents often want access to events without the obligation to attend. This might suggest that those with high expectations for socialization may be disappointed with the frequency of activities offered by some cohousing communities.

The physical design of many cohousing developments is also intended to facilitate socialization through the careful placement of centrally located common spaces, use of clear sight lines and smaller units to encourage interaction (Williams, 2005) (Figures 3 and 4). The non-hierarchal structure of cohousing management may also help reduce barriers and encourage participation among residents (2005). However, because of the collaborative nature of the design and development process, developing cohousing can be a time-consuming and difficult process.

Overall, residents of cohousing often rate this type of housing very highly. One study reports that 53.6 percent of respondents rated living conditions as very good and another 41.4 percent rated it as good (Choi, 2004). Furthermore, many residents report high satisfaction, with 97.8 percent of respondents indicating that they would recommend cohousing (2004).

Cohousing is currently being developed on a very small scale in Canada. There are currently nine completed cohousing projects and another eight either under construction or in planning process (Canadian Senior Cohousing, n.d.c). This compares with approximately 90 cohousing communities in the United States (Glass, 2009), 2,100 developments in the Netherlands and 2,800 developments in Sweden (Choi, 2004). The development of cohousing in Europe has often been undertaken under various government housing programs, reducing obstacles. Seniors cohousing may represent one of many options for "elderly people who are comparatively younger, more active, and who seek higher quality of life through communal living with others" (Choi, 2004, p. 1190). 

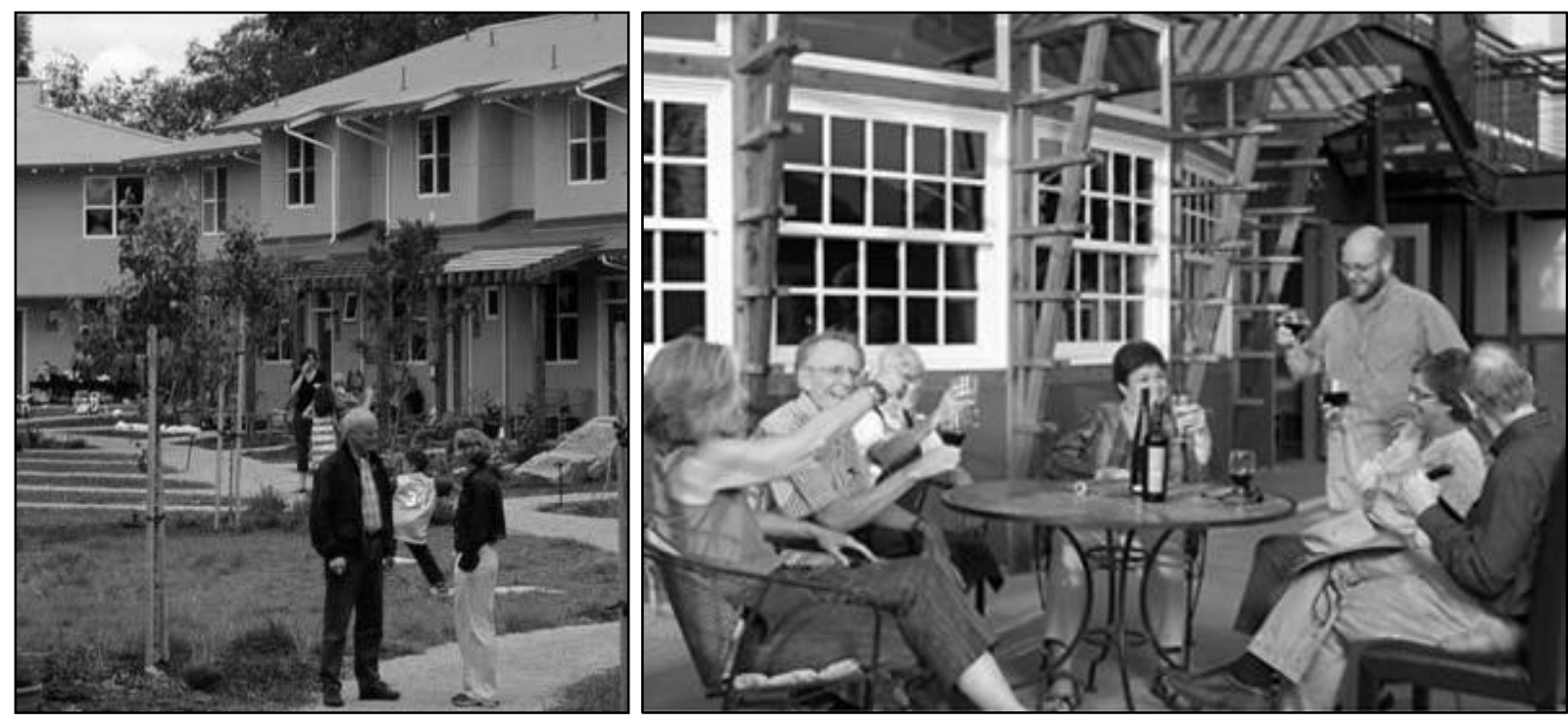

Figure 3 and 4. Pleasant Hill Cohousing Community, Pleasant Hill, California (left). Silver Sage Senior Cohousing, Boulder, Colorado (right). Note: Left from, The Cohousing Company McCamant \& Durrett Architects, 2009. Right from, Silver Sage Village, 2008.

\subsubsection{Home Sharing}

Home sharing describes a living arrangement whereby "at least two unrelated persons live together in a single dwelling unit, and each has a private space while sharing common areas such as bathroom, kitchen, living, and dining rooms" (Blackie, 1984, p. 133). Senior home sharing may include a senior renting a room in his or her home to another individual, or being a tenant in a home sharing arrangement. Matches may be informally arranged (naturally occurring) or alternatively, organized more formally through an agency or organization who assists with the screening process.

Home sharing offers a number of benefits to seniors, such as companionship (Novak, 2009; Blackie, 1984). Individuals who home share are generally less lonely, more healthy and feel safer (Stich 2000, as cited in Novak, 2009). Similarly, Blackie (1984) indicates, home sharing "can over-come isolation and loneliness and engender a feeling of safety and security" (p. 148). Other benefits include a more efficient use of the existing housing stock, a source of income for homeowners, affordable accommodation for renters, the provision of informal care and maintained ties with the community (Blackie, 1984).

A number of studies suggest that companionship is a key motivation among people participating in home sharing. Research indicates that homeowners are most often interested in home sharing for financial reasons or to combat loneliness (Blackie, 1984; Pynoos, Hamburger \& June, 1990; Rapelje, 1984). Similarly, a survey of home sharing agencies by Gutman et al. (1989) finds that the most frequent 
reason among both providers and seekers of home sharing was companionship, at 58.5 percent and 51.7 percent, respectively. The proportion of seniors who are homeowners and seeking to share their home for the purposes of companionship has been found to increase with age, while the percentage decreases among those seeking home sharing (Gutman et al., 1989). A study of 144 home share matches found that the matches were generally conducive to the creation of new friendships, with nearly half of the matches reporting moderate or strong levels of friendship (Pynoos, Hamburger \& June, 1990).

Home sharing may have some disadvantages, including a loss of privacy (Novak, 2009), while perceived obstacles include a lack of public awareness, a fear of strangers, a shortage of seekers and language and cultural barriers (Gutman et al., 1989). Gutman et al. (1989) also find that the number homeowners interested in providing home sharing often outnumbers the number of individuals seeking accommodations (1989). Moreover, the average length of matches has been reported to be less than one year, often only six to twelve months (Rapelje, 1984). Incompatibility and irreconcilable differences are often reported as the primary causes of breakup between providers and seekers (Blackie, 1984; Gutman et al., 1989). However, these findings conflict with other findings that indicate that incompatibility is not a significant cause of breakup (Rapelje, 1984).

The potential for home sharing is likely large, given the number of empty bedrooms across the country, which represents an initial indicator of the potential for home sharing. Baxter, Smerdon and Ramlo (2000) report that in 1996, there were 3.2 million empty bedrooms in households with maintainers 45 and above. The authors also report that 78 percent of all empty bedrooms were in ground-oriented dwellings. Given the trend to age in place and the large numbers of seniors living in owner-occupied detached dwellings, there is potential for home sharing in the future to not only reduce housing costs but to provide a living arrangement with potential to provide companionship.

\subsubsection{Congregate Housing}

Congregate housing is a supportive and service-enriched housing option for seniors. Congregate housing may offer a range of services, which generally vary depending on the setting and provider. These services may include meals, recreation and activities, health and personal care (Novak, 2009). In Canada, congregate housing has been developed by Abbeyfield Houses Society of Canada. Abbeyfield Houses Society of Canada is a charitable organization, which oversees local societies and is managed by a board. The Abbeyfield model of congregate housing provides small scale housing for seniors and people with disabilities. The mission of Abbeyfield Houses is to provide "a warm, family-style house and a balance between privacy and companionship, security and independence, combined with the special 
caring element provided by dedicated volunteers and the consistency of a single house manager" (Abbeyfield Houses Society of Canada, n.d.a, para. 2). The Abbeyfield model for congregate housing was developed in the United Kingdom in the mid-1950s. Its founder, Major Richard Carr-Gomm, a former army officer, developed the first Abbeyfield house in response to what he saw as a high prevalence of loneliness among older individuals. The model in the United Kingdom has since spread and today there are more than 700 houses serving more than 7,000 residents in the United Kingdom alone (Abbeyfield, 2010).

Each Abbeyfield house typically provides accommodation to ten or more residents, each having their own self-furnished bed-sitting room and a private or shared bathroom (Figures 5 and 6). Abbeyfield residents are most often singles, although couples are permitted. Residents share common areas, including living and dining areas, cooking facilities, laundry facilities and outdoor spaces. Abbeyfield housing is often constructed in existing homes of sufficient size or as purpose-built structures. Furthermore, the house is managed by a paid house coordinator, who typically provides two meals per day and housekeeping to the common areas.

Congregate housing provides residents with a number of benefits. Congregate living reduces isolation, providing residents with a greater sense of safety and emotional security (Novak, 2009) and helps to combat the loneliness experienced by vulnerable older individuals living in their homes (Novak \& Campbell, 2001). Furthermore, most Abbeyfield houses are integrated into regular neighborhoods that provide good access to amenities and services. However, despite these benefits, the model is challenged by difficulty obtaining funding, keeping the model relevant for the changing needs of seniors and ensuring full occupancy to remain financially feasible (Abbeyfield, 2010). Furthermore, because of a lack of medical services onsite, congregate housing may require residents to meet certain criteria, including being mobile and capable of managing relatively unassisted.

Today, congregate housing which follows the Abbeyfield Housing model is being built on a very small scale. There are currently 28 Abbeyfield houses across Canada, with the majority located in British Columbia, and more than 800 homes and 8,000 residents worldwide (Abbeyfield Houses Society of Canada, n.d.b.). 

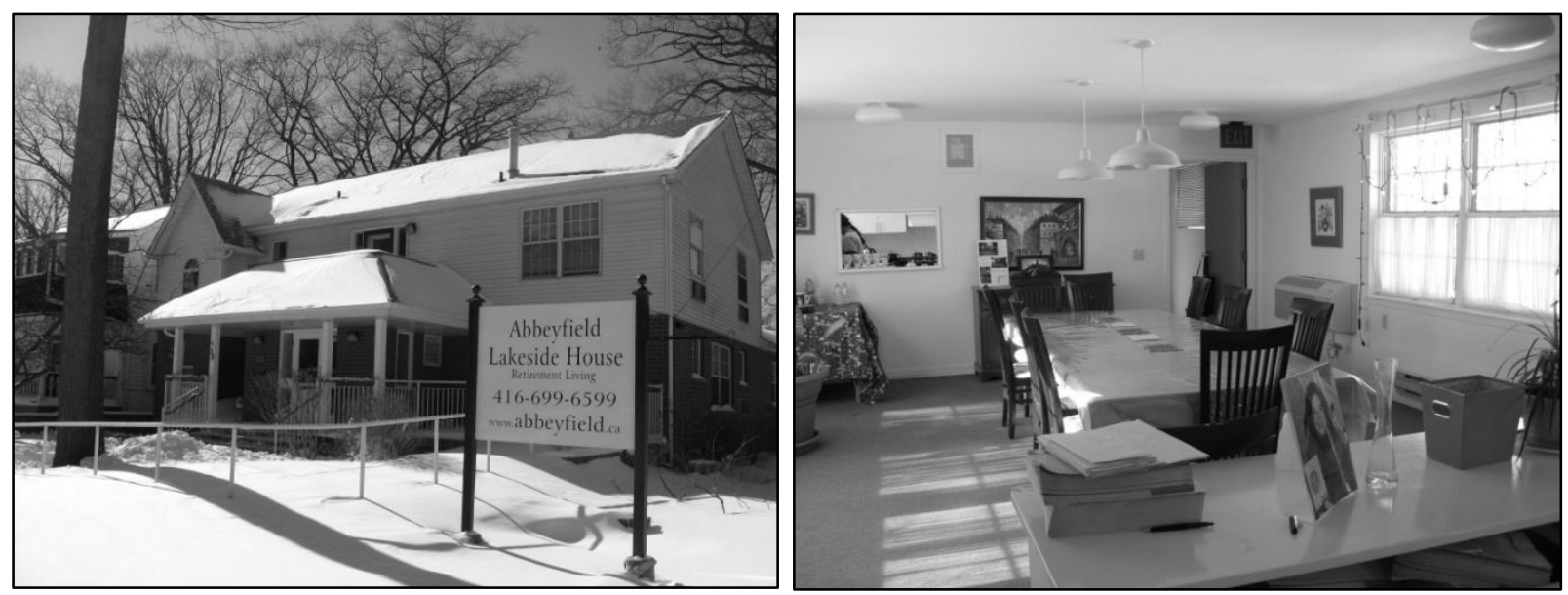

Figure 5 and 6. Abbeyfield Lakeside House, Toronto. Note: From, Wardle, 2013.

\subsubsection{Garden Suites}

A garden suite is a temporary or modular, detached residential dwelling, which generally contains a living area, cooking facilities, a single bedroom and washroom (Figures 7 and 8 ). Garden suites are designed to be temporary structures that are typically installed in the rear or side portion of the property of a family member or friend. The units are eventually removed when they are no longer required. Garden suites are commonly referred to as granny flats in Australia and Britain, elder cottages or elder cottage housing opportunities (ECHO) in the United States and portable living suites for seniors (PLUS) or garden suites in Canada. The first formal garden suite program was established in 1975 in the State of Victoria, Australia (Ministry of Housing, 1990). The “Moveable Units" program was implemented by the State government, which created legislation to permit garden suites in most municipalities. The program continues to this day, providing garden suite rentals to individuals who are aged 55 and above and who meet certain income requirements (State Government of Victoria, 2011).

Historically, garden suites have been promoted as housing specifically for seniors and to a lesser extent, people with disabilities. The garden suite is typically developed for use by an elderly family member, while the primary dwelling is occupied by the "host family", often family or friends who may provide informal care and support. The garden suite concept offers many potential benefits to occupants, host families and the broader community. Garden suites allow occupants to live relatively independently, providing privacy for both households and facilitating aging in place an intergenerational living setting. For some seniors, garden suites are considered a relatively affordable housing option (CMHC, 1995; MMAH, 2011). However, the lack of a national or provincial garden suite program makes this option less affordable in Canada. A version of the garden suite constructed by MEDCottage in the United States 
currently leases for $\$ 1,400$ to $\$ 1,700$ per month Canadian or may be purchased for approximately $\$ 87,000$ (Langston, 2012).

A number of garden suite projects were undertaken in Canada in the 1980s as interest in alternative housing options emerged. These included several demonstration projects, including the Portable Living Units for Seniors (P.L.U.S.) project across Ontario and the Garden Suites Demonstration: National Survey. The three year P.L.U.S. demonstration project, starting in 1985, included the installation of 12 garden suites across Ontario. A follow-up survey of participating occupants and host families found that garden suites facilitated support and companionship and that participants generally reported closer family relationships (CMHC, 1995). The survey also reported that garden suites were a healthy aging environment, helped reduce public service demand, delayed institutionalization, made larger homes available to families and did not have an impact on the character of the community (1995).

Today, garden suites are promoted as a housing option in a small number of Canadian communities, although the number of completed suites is likely very small. Garden suites are permitted in the Province of Ontario under the Planning Act and policies have now been adopted the Towns of Caledon and Bradford West Gwillimbury, among others. In some instances, the original purpose of providing housing for seniors has been abandoned in favor of a more inclusive policy on occupancy not limited to seniors. Overall, despite a number of potential benefits, garden suites have failed to receive significant interest due to restrictive land use regulations, poor marketing of the concept and a lack of nonownership options (Ministry of Housing, 1990). Regulatory barriers may include a lack of zoning, complex removals, issues with ensuring removal of the unit (CMHC, 1995) and fear of lowered property values and cost.
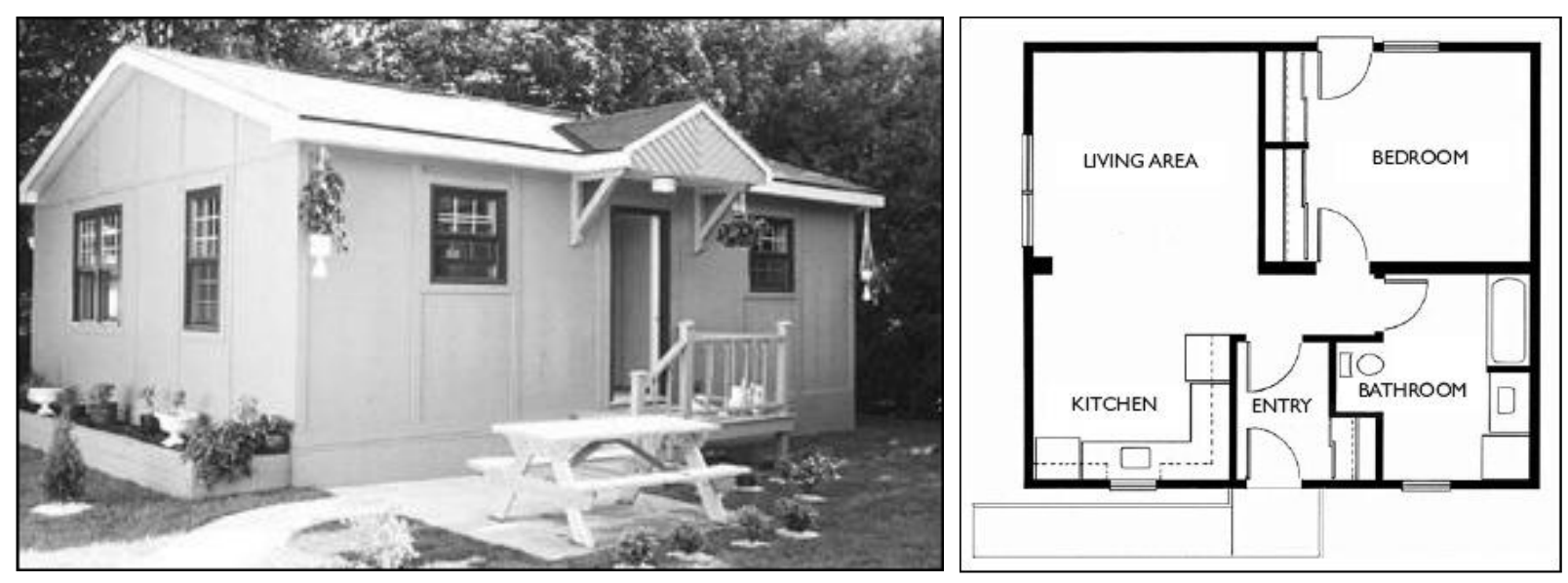

Figure 7 and 8. Garden suite and plan. Note: From, Canadian Mortgage and Housing Corporation, n.d.c. 


\subsubsection{Summary}

A number of housing options are presented. Each option provides some potential to encourage greater socialization or provide companionship. However, a number of challenges are also described. The following section provides a critical discussion, discussing each housing option in relation to key themes identified in the literature review on social isolation and loneliness. 


\subsection{DISCUSSION}

Prepared or not, many communities across Canada are already experiencing an increase in their seniors population. Preparing for an aging population has placed great emphasis on modifying the home for this coming gray wave. While many seniors will have the appropriate supports to remain in their homes and communities safely, social and demographic trends suggest that others may be living in housing that is inadequate in meeting their social and emotional needs for socialization and companionship. Issues of social isolation and loneliness have received relatively little attention in comparison, with few housing options promoted or widely available for the purpose of alleviating these problems. These issues are important because both the objective experience of social isolation and subjective experience of loneliness have been linked to significant negative outcomes for health and wellbeing.

Four housing alternatives are presented above. Based on key themes identified in the literature on social isolation and loneliness, each of the options is discussed below with regards to its potential to help respond to these issues.

\subsection{Can Housing Reduce Social Isolation and Loneliness? Four Options}

Four housing options, cohousing, congregate housing, home sharing and garden suites were presented, each possessing characteristics with some potential for reducing social isolation and alleviating loneliness.

Cohousing, congregate housing, home sharing and garden suites all create new opportunities for social relationships and companionship. Cohousing provides opportunities for neighbourly interactions, which the literature suggests may be preferred by some individuals and have an impact on reducing loneliness. Residents are able to participate in a range of activities not limited to meetings, shared meals and neighborly exchanges. The smaller size of the units encourages greater use of common areas, promoting socialization. A study of over 500 residents in 28 senior cohousing developments in Sweden and Denmark found that three quarters felt the number of shared activities was just right; however, slightly less than a quarter indicated a desire for more frequent activities (Choi, 2004). If these findings are consistent with other cohousing developments, the frequency of social activities may not be sufficient for some residents. Other options such as congregate housing and home sharing provide daily contact with others, including shared meals and shared use of common areas, which can help reduce social isolation. However, one study of home sharing matches in the Niagara region in Ontario found that 
matches typically lasted less than one year (Rapelje, 1984). For those individuals seeking to develop meaningful new friendships, the degree to which this can be accomplished within a relatively short period of time is questionable. Garden suites have also been developed for the purpose of providing support, particularly from family. However, the garden suite concept does not offer the same degree of access to social activities, including the opportunity to make new friends. Occupants may be reliant on the host family to help facilitate access to activities outside of the home. Some research also suggests that while some seniors experience reduced loneliness from living in proximity to an adult child, others experience increased loneliness when residing with their adult children (Wenger \& Burholt, 2004).

Advancing age has also been identified as an indirect risk factor for social isolation and loneliness because of the effect of declining health and other factors associated with increasing age. Older adults with physical limitations, disabilities and who are in poor health are also consistently among identified in the literature as reporting greater social isolation and loneliness. While several of these options, particularly cohousing, congregate housing and garden suites may be designed to accommodate people with disabilities, many of the options are designed for relatively healthy and independent seniors. Despite the benefits of a number of these housing options, not all have been designed to safely house individuals with more limited mobility or significant health issues. The seniors cohousing model has been developed to facilitate aging in place, including incorporating accessible design. A key principle of seniors cohousing is also the principle of "co-care" principle, whereby neighbours provide support and assistance to one another. However, co-care is not a replacement for formal medical care. The development process for new cohousing projects may also be a challenging, lengthy and time-consuming process that requires interested parties to navigate the planning system. For some seniors, this process may be too cumbersome and may not be timely enough to meet their housing needs.

Other options, such as congregate housing are also designed to be accessible for older individuals; however, many homes require residents to meet basic requirements with regards to their ability to perform tasks unassisted, such as getting in and out of bed and moving throughout the home to attend meals. Similar to other types of housing, home sharing living arrangements may not be suitable for people with disabilities or who are in poor health. Dwellings may not be suitable for aging in place due to a lack of modifications and poor access to transit, amenities and services. Individuals with mobility and health limitations may also face challenges in finding a home share arrangement due to reluctance on the part of the homeowner to be placed with someone with complex health and mobility issues. The last option, the garden suite, was created with the purpose of providing accessible and supportive housing for seniors. The physical design of the suite may be suitable for individuals with health and mobility 
limitations; however, similar to home sharing, access to transit, amenities and services may be poor, having an isolating affect. The placement of the garden suite on the property of an adult child may also require a move to a new community, reducing access friends, neighbours and familiar places and routines.

Cost of housing another significant consideration for seniors, whose incomes are often lower than non-senior households. The literature suggests that those who are socio-economically disadvantaged may be more vulnerable to loneliness. In general, homeownership rates among seniors decline with advancing age, while the proportion of senior renter households increases. Home sharing and congregate housing provide more affordable options, particularly home sharing where help with household tasks can be exchanged for reduced rent. Congregate housing provided by Abbeyfield Houses Society provides another relatively inexpensive housing option. Other options, including cohousing and garden suites may be relatively expensive and not an option available to some seniors.

Each of the four housing options has some potential to reduce social isolation and alleviate loneliness. While the literature suggests those reporting poor health and disabilities are among the most likely to report feeling lonely, without extensive home care and other services, none of the housing options presented are designed for seniors with complex health problems. Several options, including cohousing, home sharing and garden suites appear to be designed for a younger and healthier segment of the seniors population. With the exception of home sharing, most of these options are currently very limited in Canada. Because of their limited development, it is very unlikely that many seniors will be able to access these options in their community. Remaining in the community is important for seniors to maintain existing social networks and access to familiar amenities and services. A move to new housing option for the purpose of reducing isolation or loneliness may be somewhat counterproductive.

It is important to note that while the literature suggests that individuals possessing certain characteristics may be more vulnerable to social isolation and loneliness, the diversity of the Baby Boomer Generation makes it difficult to make sweeping conclusions to assess the suitability of housing. Each option presents a number of opportunities but is similarly faced with challenges. Subsequently, no one housing option is suitable for all seniors. The importance of personal characteristics, background, values and expectations of social relationships must not be understated, further underscoring the complexity of this important but challenging issue. 


\subsection{Challenges for Planners}

Planners will encounter many challenges with this complex and deeply personal issue. The diversity of the Baby Boomer Generation is one significant challenge. It is not yet known what effect or what preferences the baby boomers will have. For many seniors, the preference to age in place, commonly within a private dwelling that offers maximum privacy and independence, is considered the most desirable option. The importance of home and its associated feelings and attachments may override the benefits of a move to a more social living environment.

A range of housing options will certainly be needed to accommodate the diversity of this generation; however, many of the shared housing options presented are only available on an extremely small scale and rarely are multiple options available in a single community. For those interested and willing to move to fulfill their social needs, the lack of availability remains a barrier. In the future, it is possible that demand for these alternatives may increase due to housing costs, the general availability of other housing options and changes to family structures which can no longer offer the same levels of support.

Another significant challenge for planners and policy makers is to respond to the need among some seniors for greater emotional closeness. While planning interventions may promote living environments that foster socialization, the literature indicates that loneliness is a complex, personal experience and the ability to establish new relationships is impacted by a number of factors, including personal capacity and interest. For some individuals, there may be potential to alleviate social loneliness by introducing new opportunities for socialization. For others individuals, however, emotional loneliness caused by a lack of a close attachment figure may not be so easily alleviated through housing or a living arrangements that introduces these opportunities. As Franklin and Tranter (2011) suggest, "policies and practices need to be developed that create relationships that matter rather than mere co-presence in the form of day rooms, social activities, outings and so on" (p. 12). Creating housing that fosters meaningful and satisfying relationships is a significant challenge for planners.

\subsection{Recommended Actions}

The literature suggests that despite the challenges, there may be some potential for housing to help reduce social isolation and alleviate loneliness. A number of actions are recommended below, outlining how planners and policy makers might take steps in the future to help address these issues. These steps include: 
- Identifying and targeting interventions towards those who are most vulnerable or who have multiple risk factors for becoming socially isolated or experiencing loneliness. Research on social isolation and loneliness suggests that individuals with certain characteristics may be more vulnerable or at risk. Furthermore, some individuals may be affected by multiple, compounding factors, such as a person who is disabled, has few social ties and a lower socioeconomic status. Identifying these individuals may be a challenge because they may not be visible in the community.

- Greater collaboration between health, gerontology and housing researchers. Greater collaboration between researchers, planners and policy makers exploring these issues is essential. Research on social isolation and loneliness has too rarely attempted link these issues to housing in a meaningful way. Specific mechanisms by which housing can be more active part of the solution must be identified.

- Incorporating social needs into the definition for housing standards. A more inclusive definition for housing standards is needed to represent all aspects, not simply those pertaining to the physical and economic elements. This could raise awareness about the role housing plays in facilitating social and emotional health.

- Investigating housing options for seniors who do not intend to move. The majority of senior indicate a desire to age in their current home. While potential social and emotional benefits are possible through alternative housing options, these options are currently not widely chosen. Living arrangements, such as home sharing, could be promoted as a cost effective alternative for seniors who desire to remain in their current home but want new opportunities for socialization and companionship.

- Removing planning and regulatory barriers to housing alternatives. Housing options for seniors is often limited, particularly in smaller communities. Removing the barriers to constructing a wider array of seniors housing options as well as increasing awareness among municipal staff is needed. For example, a greater awareness of cohousing among municipalities is required to streamline the development process. Municipalities should consider facilitating or partnering with other organizations to deliver home sharing support services, congregate housing and other services.

- Promoting and improving awareness of alternative housing options. The Baby Boomer Generation will likely require a more diverse stock of housing and living options than are currently available. The discussion suggests that given the complexity of the issue and diverse personal 
characteristics and beliefs, no one housing option will alleviate all instances of loneliness. A range of housing options is needed, which must occur in conjunction with a greater awareness among seniors.

- Involving seniors in the planning process. Interventions aimed to reduce social isolation and loneliness among seniors must be designed in partnership with seniors themselves.

\subsection{Areas for Further Study}

The literature review and discussion has identified a number of areas where further research is needed. These areas include,

- Exploring the ability of housing to respond to emotional loneliness. Emotional loneliness appears to be less easily ameliorated by the introduction of new people. Further research is needed to explore whether different housing options can address this particular type of loneliness and help create the emotionally close relationships desired by some lonely people.

- Exploring the gendered aspects of social isolation and loneliness. The literature suggests that social isolation and loneliness are gendered experiences. This suggests that different interventions may be needed to address these issues in men and women. Further housing research should explore whether these and other housing alternatives are deemed acceptable to men and women and whether certain options present barriers for either gender.

- Exploring how different cultures might respond to these options. Similar to gender, the literature on loneliness, in particular, suggests that culture has a bearing on the incidence of social isolation and loneliness. Further research is needed to explore whether these housing alternatives are culturally appropriate and if additional options are required to address these issues among different ethnic groups.

Social isolation and loneliness are emergent and important issues for planning. Plans and policies that take into account an individual's physical and economic needs for adequate, affordable and suitable housing are essential; however, these elements represent only part of the solution. Recognizing the importance of social networks and emotional well-being is essential to ensure a successful and healthy aging of the population in the years to come. 


\section{REFERENCE LIST}

Abbeyfield Houses Society of Canada. (n.d.a.). Interested in becoming a resident in an Abbeyfield House? Retrieved March 202013 from, http://www.abbeyfield.ca/residency.html

Abbeyfield Houses Society of Canada (n.d.b). What is abbeyfield? Retrieved March 202013 from, http://www.abbeyfield.ca/about-us.html

Abbeyfield. (2010). Abbeyfield - A Summary of the Strategy for Growth 2010. Retrieved from, http://www.abbeyfield.com/media/329840/abridged_strategy_v3.pdf

Baxter, D., Smerdon, J. and A. Ramlo (2000). Changing Places: A Strategy for Homeownership, Residential Neighbourhoods, and RRSPs in Canada. The Land Institute. Retrieved from, http://www.urbanfutures.com/reports/Report\%2045.pdf

Bayer, A. and L Harper. (2000). Fixing to Stay: A National Survey of Housing and Home Modification Issues. American Association of Retired Persons (AARP). Retrieved from, http://assets.aarp.org/rgcenter/il/home_mod.pdf

BC Ministry of Health. (2004). Social Isolation Among Seniors: An Emerging Issue. Retrieved from, http://www.health.gov.bc.ca/library/publications/year/2004/Social_Isolation_Among_Seniors.pdf

Blackie, N. (1984). Chapter 10: Shared Housing: Principles and Practices. (p. 133 - 153). In, Gutman, G. and N. Blackie. (1984). Innovations in Housing and Living Arrangements for Seniors. Burnaby, BC: The Gerontology Research Centre, Simon Fraser University.

Brink. S. (1985). Housing Elderly People in Canada: Working Towards a Continuum of Housing Choices Appropriate to Their Needs. Chapter 1. (p. 1 - 23). In, Gutman, G. and N. Blackie. (1985). Innovations in Housing and Living Arrangements for Seniors. Burnaby, BC: Gerontology Research Centre, Simon Fraser University.

Cacioppo, J. and W. Patrick. (2008). Loneliness: Human Nature and the Need for Social Connection. New York, NY: W. W. Norton \& Company.

Cacioppo, J., Hawkley, L., Crawford, E., Ernst, J., Burleson, M., Kowalewski, R., Malarkey, W., Cauter, E. and G. Berntson. (2002). Loneliness and Health: Potential Mechanisms. Psychosomatic Medicine. 64: $407-417$.

Canadian Institute for Health Information (ClHI). (2011). Health Care Cost Drivers: The Facts. Ottawa, ON: ClHI. Retrieved from, https://secure.cihi.ca/free_products/health_care_cost_drivers_the_facts_en.pdf 
Canadian Mortgage and Housing Corporation. (2012). Housing for Older Canadians: The Definitive Guide to the Over-55 Market. Ottawa, ON: Canadian Mortgage and Housing Corporation.

Canadian Mortgage and Housing Corporation. (2011). Canadian Housing Observer 2011. Ottawa, ON: Canadian Mortgage and Housing Corporation.

Canadian Mortgage and Housing Corporation. (2008). Impacts of the Aging of the Canadian Population on Housing and Communities. Ottawa, ON: Canadian Mortgage and Housing Corporation.

Canadian Mortgage and Housing Corporation. (1995). The Complete Guide to Garden Suites (Part 1). Ottawa: Canadian Mortgage and Housing Corporation.

Canadian Mortgage and Housing Corporation. (n.d.a). Cohousing Strategy. Retrieved March 12013 from, http://www.cmhcschl.gc.ca/en/inpr/afhoce/afhoce/afhostcast/afhoid/cohode/cost/cost_002.cfm

Canadian Mortgage and Housing Corporation. (n.d.b). Housing in Canada Online: Definition of Variables. Retrieved March 202013 from, http://cmhc.beyond2020.com/HiCODefinitions_EN.html

Canadian Mortgage and Housing Corporation. (n.d.c.). Garden Suites. Retrieved April 102013 from, http://www.cmhc.ca/en/co/renoho/refash/refash_026.cfm

Canadian Senior Cohousing. (n.d.a). What is senior cohousing?. Retrieved March 1 2013, from, http://canadianseniorcohousing.com/?page_id=6

Canadian Senior Cohousing. (n.d.b). Co-care. Retrieved March 1 2013, from, http://canadianseniorcohousing.com/?page_id=993

Canadian Senior Cohousing. (n.d.c). Cohousing Movement. Retrieved March 202013 from, http://canadianseniorcohousing.com/?page_id=13

Cheal, D. (ed). (2002). Aging and Demographic Change in Canadian Context. Toronto, ON: University of Toronto Press.

Choi, J. (2004). Evaluation of Community Planning and Life of Senior Cohousing Projects in Northern European Countries. European Planning Studies. 12(8): 1189 - 1216.

Cloutier-Fisher, D., Kobayashi, K. and A. Smith. (2011). The subjective dimension of social isolation: A qualitative investigation of older adults experiences in small social support networks. Journal of Aging Studies. 25: 407 - 414.

Cloutier-Fisher, D. and K. Kobayashi. (2009). Examining social isolation by gender and geography: conceptual and operational challenges using population health data in Canada. Gender, Place and Culture. 16(2): 181 - 199. 
The Cohousing Company McCamant \& Durrett Architects. (2009). Pleasant Hill Cohousing Community, Pleasant Hill, California. Retrieved April 12013 from, http://cohousingco.com/project-details.cfm?select=pleasant-hill\&cat=cohousing-communities

Cranswick, K. and D. Dosman. (2008). Eldercare: What we know today. Statistics Canada. Retrieved from, http://www.statcan.gc.ca/pub/11-008-x/2008002/article/10689-eng.htm

de Jong-Gierveld, J. (1998). A review of loneliness: concept and definitions, determinants and consequences. Reviews in Clinical Gerontology. 8: 73 - 80.

Durrett, C. (2009). The Senior Cohousing Handbook. 2nd edition. Gabriola Island, BC: New Society Publishers.

Dykstra, P. (1990). Next of (Non)Kin: The Importance of Primary Relationships for Older Adults' Wellbeing. Medical Anthropology Quarterly, New Series. 6(2): 171 - 173.

Dykstra, P. (2009). Older adult loneliness: myths and realities. European Journal of Aging. 6: 91 - 100.

Federal/Provincial/Territorial Committee of Officials (Seniors). (2006). Healthy Aging in Canada: A New Vision, A Vital Investment. From Evidence to Action. Retrieved from, http://www.health.gov.nl.ca/health/publications/vision_rpt_e.pdf

Federal/Provincial/Territorial Ministers Responsible for Seniors. (2007). Age-Friendly Rural Communities: A Guide. Retrieved from, http://www.phac-aspc.gc.ca/seniors-aines/publications/public/afc-caa/rural-rurales/indexeng.php

Franklin, A. and B. Tranter. (2011). AHURI Essay: Housing, loneliness and health. Australian Housing and Urban Research Institute. Retrieved March 72013 from, http://www.ahuri.edu.au/publications/download/40601_fr

Gilmour, H. (2012). Social participation and the health and well-being of Canadian seniors. Statistics Canada. Retrieved from, http://www.statcan.gc.ca/pub/82-003-x/2012004/article/11720eng.htm

Glass, A. (2009). Aging in a Community of Mutual Support: The Emergence of an Elder Intentional Cohousing Community in the United States. Journal of Housing for the Elderly. 23: 283 - 303.

Goodwin, R., Cook, O., and Y. Yung. (2001). Loneliness and life satisfaction among three cultural groups. Personal Relationships. 8: 225 - 230.

Government of Canada. (2013a). Indicator of Well-being in Canada. Canadians in Context - Aging Population. Retrieved from, http://www4.hrsdc.gc.ca/.3ndic.1t.4r@-eng.jsp?iid=33 
Government of Canada. (2013b). Indicators of Well-Being in Canada. Canadians in Context - Households and Families. Retrieved from, http://www4.hrsdc.gc.ca/.3ndic.1t.4r@-eng.jsp?iid=37

Gutman, G., Doyle, V., Melliship, K., and P. Baldwin. (1989). A Survey of Canadian Home sharing Agencies Serving the Elderly. Burnaby, BC: Gerontology Research Centre. Simon Fraser University.

Hall, M. (2004). Report on the FPT Expert Consultation: Workshop on Social Isolation and Seniors. Retrieved from, http://www.health.gov.bc.ca/library/publications/year/2004/ Social_isolation_workshop_report.pdf

Hall, M., Havens, B. and G. Sylvester. (2003). The Experience of Social Isolation and Loneliness Among Older Men in Manitoba. Retrieved from, http://www.veterans.gc.ca/pdf/pro_research/social-isol-loneliness-vac-report.pdf

Hallman, B. and A. Joseph. (1997). Chapter 7: Housing the Rural Elderly: A Place for Abbeyfield? Journal of Housing For the Elderly. 12(1-2): 83 - 103.

Harris, M. (2012, June 11). What's Better for Old People: City or Suburb? MinnPost. Retrieved from, http://www.minnpost.com/cityscape/2012/06/what\%E2\%80\%99s-better-old-people-city-orsuburb

Havens, B., Hall, M., Sylvester, G. and T. Jivan. (2004). Social Isolation and Loneliness: Differences between Older Rural and Urban Manitobans. Canadian Journal on Aging. 23(2): 129 - 140.

Hall, M., \& Havens, B. (1999). The effects of social isolation and loneliness on the health of older women. Report prepared for the Prairie Women's Health Centre of Excellence. Winnipeg, MB: University of Manitoba.

Heylen, L. (2010). The older, the lonelier? Risk factors for social loneliness in old age. Ageing \& Society. 31: $1177-1196$.

Hodge G. (2008). The Geography of Aging: Preparing Communities for the Surge in Seniors. Montreal: McGill-Queen's University Press.

Holt-Lunstad, J., Smith, T., and J. Bradley Layton. (2010). Social Relationships and Mortality Risk: A Metaanalytic Review. PLOS Medicine. 7(7): 1 - 20.

Jylha, M. (2004). Old Age and Loneliness: Cross-sectional and Longitudinal Analyses in the Tampere Longitudinal Study on Aging. Canadian Journal on Aging. 23(2): 157 - 168.

Koropeckyj-Cox, T. (1998). Loneliness and Depression in Middle and Old Age: Are the Childless More Vulnerable. The Journals of Gerontology. 53B(6): 303 - 312.

Langston, P. (2012). Choice can be difficult for aging boomers. The Ottawa Citizen. Retrieved from, http://www.ottawacitizen.com/life/Choice+difficult+aging+boomers/6800967/story.html 
Ministry of Housing. Government of Ontario. (1990). Portable Living Units for Seniors (P.L.U.S.) or 'Granny Flat' Demonstration Project: Summary Report. Toronto, ON: Ministry of Housing.

Ministry of Municipal Affairs and Housing. (2011). Municipal Tools for Affordable Housing. Retrieved from, http://www.mah.gov.on.ca/AssetFactory.aspx?did=9270

Mullins, L. (1996). Social determinants of Ioneliness among older Americans. Genetic, Social \& General Psychology Monographs. 122(4): 453 - 473.

Mullins, L., Johnson, P. and L. Anderson. (1987). Loneliness in the Elderly: The Impact of Family and Friends. Journal of Social Behavior and Personality. 2(2): 225 - 238.

Novak, M. (2009). Issues in Aging. Boston: Pearson.

Novak, M. and L. Campbell. (2001). Aging \& Society: a Canadian perspective. Scarborough, ON: Nelson Thompson Learning.

Paũl, C. and O. Riberio. (2009). Predicting loneliness in old people living in the community. Reviews in Clinical Gerontology. 19: 53 - 60.

Peissinotto, C., Stijacic, I. and K. Covinsky. (2012). Loneliness in Older Persons: A Predictor of Functional Decline and Death. Archives of Internal Medicine. 172(14): 1078 - 1083.

Perlman, D. (2004). European and Canadian Studies of Loneliness among Seniors. Canadian Journal on Aging. 23(2): 181 - 188.

Peters, R. (2004). Research Snapshots: Social Isolation and Loneliness. Retrieved from, http://www.coag.uvic.ca/resources_research_snapshots_social_isolation.htm

Pynoos, J., Nishita, C., Cicero, C. and R. Caraviello. (2008). Aging in Place, Housing, and the Law. The Elder Law Journal. 16(1): 77 - 105.

Pynoos, J., Hamburger, L. and A. June. (1990). Supportive Relationships in Shared Housing. Journal of Housing for the Elderly. 6(1-2): 1 - 24.

Rapelje, D. (1984). A Canadian Example: The Home Sharing Program for Older Adults in Regional Niagara. Chapter 11. (p.153-165). In, Gutman, G. and N. Blackie. (1984). Innovations in Housing and Living Arrangements for Seniors. Burnaby, BC: The Gerontology Research Centre, Simon Fraser University.

Raphael, D. and J. Mikkonen. (2010). The Social Determinants of Health: The Canadian Facts. Retrieved from, http://www.thecanadianfacts.org/The_Canadian_Facts.pdf

Routasalo, P., Savikko, N., Tilvis, R., Strandberg, T. and K. Pitkälä. (2006). Social Contracts and Their Relationship to Loneliness among Aged People - A Population-Based Study. Gerontology. 52: 181 $-187$. 
Russell, D., Cutrona, C., de la Mora, A. and R. Wallace. (1997). Loneliness and Nursing Home Admission Among Rural Older Adults. American Psychological Association Inc. 12(4): 574 - 589.

Schriener, J. and M. Kephart. (2010). Building for Boomers: Guide to Design and Construction. New York: McGraw-Hill.

Silver Sage village. (2008). Silver Sage Village. Retrieved April 1 2013, from, http://silversagevillage.com/

State Government of Victoria. (2011). Movable Units. Department of Human Resources. Retrieved from, http://www.dhs.vic.gov.au/for-individuals/housing-and-accommodation/home-ownersupport/movable-units

Statistics Canada. (2013). Canadian households in 2011: Type and growth: Families, households and marital status, 2011 Census of Population (Report no. 98-312-X2011003). Ottawa: Ministry of Infrastructure.

Statistics Canada. (2012a). Census in Brief: Generations in Canada. Age and sex, 2011 Census (Report no. 98-311-X2011001). Ottawa: Ministry of Infrastructure.

Statistics Canada. (2012b). Living arrangements of seniors (Report Catalogue no. 98-312-X2011003). Ottawa: Ministry of Infrastructure.

Statistics Canada. (2012c). Census in Brief: Fifty years of families in Canada: 1961 to 2011 (Report Catalogue no. 98-312-X2011003). Ottawa: Ministry of Infrastructure.

Statistics Canada. (2011a). Census of Population, 2011. Retrieved from, http://www12.statcan.gc.ca/census-recensement/2011/as-sa/98-312x/2011003/fig/desc/desc3_4-1-eng.cfm

Statistics Canada. (2010a). Population Projections for Canada, Provinces and Territories 2009 to 2036 (Report no. 91-520-X). Ottawa: Ministry of Infrastructure.

Turcotte, M. and G. Schellenberg. (2006). A Portrait of Seniors in Canada: Introduction (Report no. 89519-XWE). Statistics Canada. Retrieved from, http://www.statcan.gc.ca/pub/89-519-x/89-519x2006001-eng.htm

van Tilburg, T., Havens, B. and J. de Jong-Gierveld. (2002). Loneliness among Older Adults in the Netherlands, Italy, and Canada: A Multifaceted Comparison. Canadian Journal on Aging. 23(2): 169 $-180$.

Victor, C., Scambler, S., Bowling, A. and J. Bond. (2000). Being alone in later life: loneliness, social isolation and living alone. Reviews in Clinical Gerontology. 10: 407 - 417.

Weeks, C. (2013, January 13). From hormones to brain function: Why living alone may be bad for your health. The Globe and Mail. Retrieved February 152013 from, 
http://www.theglobeandmail.com/life/health-and-fitness/health/from-hormones-to-brain-functionwhy-living-alone-may-be-bad-for-your-health/article7251467/

West, D., Kellner, R. and M. Moore. (1986). The Effects of Loneliness. A Review of the Literature. Comprehensive Psychiatry. 27(4): 351 - 363.

Weiss, R. (1973). Loneliness: The Experience of Emotional and Social Isolation. Cambridge, MA: The MIT Press.

Wenger, G. and V. Burholt. (2004). Changes in Levels of Social Isolation and Loneliness among Older People in a Rural Area: A Twenty-Year Longitudinal Study. Canadian Journal on Aging. 23(2): 115 127.

Williams, J. (2005). Sun, Surf and Sustainable Housing - Cohousing, the California Experience. International Planning Studies. 10(2): 145 - 177.

World Health Organization (WHO). (2013). Risk factors of ill health among older people. Retrieved from, http://www.euro.who.int/en/what-we-do/health-topics/Life-stages/healthy-ageing/facts-andfigures/risk-factors-of-ill-health-among-older-people

World Health Organization. (2007). Global Age-friendly Cities: A Guide. Retrieved from, http://www.who.int/ageing/publications/Global_age_friendly_cities_Guide_English.pdf 